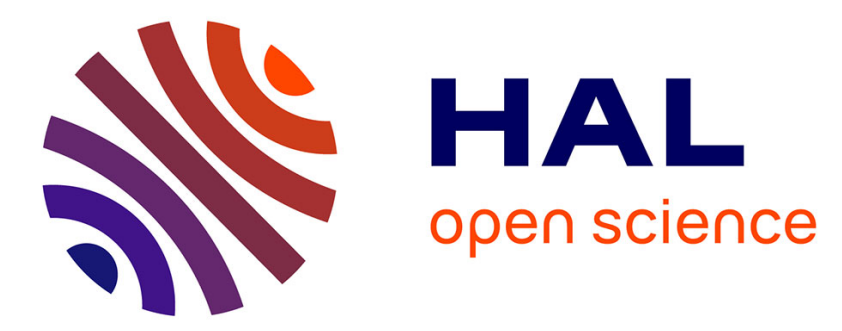

\title{
Stress-Strain Evolution During Peak-Ring Formation: A Case Study of the Chicxulub Impact Structure
}

Auriol Rae, Gareth Collins, Michael Poelchau, Ulrich Riller, Thomas Davison, Richard Grieve, Gordon Osinski, Joanna Morgan, S. P. S. Gulick, Elise Chenot, et al.

\section{To cite this version:}

Auriol Rae, Gareth Collins, Michael Poelchau, Ulrich Riller, Thomas Davison, et al.. Stress-Strain Evolution During Peak-Ring Formation: A Case Study of the Chicxulub Impact Structure. Journal of Geophysical Research. Planets, 2019, 124 (2), pp.396-417. 10.1029/2018JE005821 . hal-02128150

\section{HAL Id: hal-02128150 \\ https://hal.umontpellier.fr/hal-02128150}

Submitted on 14 May 2019

HAL is a multi-disciplinary open access archive for the deposit and dissemination of scientific research documents, whether they are published or not. The documents may come from teaching and research institutions in France or abroad, or from public or private research centers.
L'archive ouverte pluridisciplinaire HAL, est destinée au dépôt et à la diffusion de documents scientifiques de niveau recherche, publiés ou non, émanant des établissements d'enseignement et de recherche français ou étrangers, des laboratoires publics ou privés. 


\section{RESEARCH ARTICLE \\ 10.1029/2018JE005821 \\ Stress-Strain Evolution During Peak-Ring Formation: A Case Study of the Chicxulub Impact Structure}

Key Points:

- Numerical impact simulations are used to track stress and strain during complex crater formation

- Stress and strain predictions allow time, orientation, and magnitude constraints on the deformational history of paraautochthonous rocks - Predicted strains are consistent with the deformation observed within rocks of the Chicxulub peak ring

Supporting Information:

- Supporting Information S1

Correspondence to:

A. S. P. Rae,

auriol.rae@geologie.uni-freiburg.de

Citation:

Rae, A. S. P., Collins, G. S., Poelchau, M. H., Riller, U., Davison, T., Grieve, R. A. F., et al. (2019). Stress-strain evolution during peak-ring formation: A case study of the chicxulub impact structure. Journal of Geophysical Research:

Planets, 124, 396-417.

https://doi.org/10.1029/2018JE005821

Received 30 AUG 2018

Accepted 24 JAN 2019

Accepted article online 31 JAN 2019

Published online 13 FEB 2019

(C)2019. American Geophysical Union. All Rights Reserved.

\author{
Auriol S. P. Rae Re $^{1}$, Gareth S. Collins ${ }^{1}$ (D), Michael Poelchau' ${ }^{2}$ Ulrich Riller $^{3}$ (D), \\ Thomas M. Davison ${ }^{1}$ (D), Richard A. F. Grieve ${ }^{4}(\mathbb{D})$, Gordon R. Osinski ${ }^{4}$ iD, Joanna V. Morgan ${ }^{1}$, \\ and IODP-ICDP Expedition 364 Scientists
}
${ }^{1}$ Department of Earth Science and Engineering, Imperial College London, London, UK, ${ }^{2}$ Institut für Geo- und Umweltnaturwissenschaften, Albert-Ludwigs-Universität Freiburg, Geologie, Freiburg, Germany, ${ }^{3}$ Institut für Geologie, Universität Hamburg, Hamburg, Germany, ${ }^{4}$ Department of Earth Sciences/Centre for Planetary Science and Exploration, Western University, London, Ontario, Canada

\begin{abstract}
Deformation is a ubiquitous process that occurs to rocks during impact cratering; thus, quantifying the deformation of those rocks can provide first-order constraints on the process of impact cratering. Until now, specific quantification of the conditions of stress and strain within models of impact cratering has not been compared to structural observations. This paper describes a methodology to analyze stress and strain within numerical impact models. This method is then used to predict deformation and its cause during peak-ring formation: a complex process that is not fully understood, requiring remarkable transient weakening and causing a significant redistribution of crustal rocks. The presented results are timely due to the recent Joint International Ocean Discovery Program and International Continental Scientific Drilling Program drilling of the peak ring within the Chicxulub crater, permitting direct comparison between the deformation history within numerical models and the structural history of rocks from a peak ring. The modeled results are remarkably consistent with observed deformation within the Chicxulub peak ring, constraining the following: (1) the orientation of rocks relative to their preimpact orientation; (2) total strain, strain rates, and the type of shear during each stage of cratering; and (3) the orientation and magnitude of principal stresses during each stage of cratering. The methodology and analysis used to generate these predictions is general and, therefore, allows numerical impact models to be constrained by structural observations of impact craters and for those models to produce quantitative predictions.
\end{abstract}

Plain Language Summary During impact cratering events, extreme forces act on rocks beneath the crater to produce deformation. Computer simulations of large impact cratering events are particularly important because the conditions of those events can never be simultaneously produced by laboratory experiments. In this study, we describe a method by which the forces and deformations that occur during cratering can be measured in computer simulations of impact cratering events. Combining this analysis with geological observations from impact structures allows us to improve our understanding of impact crater formation. Here, we use this method to study the Chicxulub impact structure, Mexico, to understand the formation of "peak rings," rings of hills found internal to the rim of large impact craters. Our analysis provides estimates of the sequence of forces and deformation during peak-ring formation. As deformation produces fractures, our analysis has important implications for how fluids flow through rocks in craters.

\section{Introduction}

Large impact craters on rocky planetary bodies possess central peaks or a ring of peaks within the crater interior (Melosh, 1989). Impact structures with these morphologies are known as complex craters (Dence, 1965). In addition to central peaks or peak rings, complex craters have substantially smaller depth-to-diameter ratios than the smaller, bowl-shaped, and so-called simple craters (Pike, 1974). The kinematics and dynamics of the process whereby transient cavities collapse to form complex morphologies is not fully resolved, particularly for peak-ring craters, which are uncommon on Earth (Melosh \& Ivanov, 1999). One of the leading models to explain the formation of peak rings is the dynamic collapse model, where peak rings form by the outward collapse of an overheightened central uplift over the inwardly slumped rim of the transient cav- 
ity (Collins et al., 2002; Grieve et al., 1981; Kring et al., 2016; Morgan et al., 2016). With the recent recovery of a drill core from the peak ring of the Chicxulub crater by the International Ocean Discovery Program (IODP) and International Continental Scientific Drilling Program (ICDP), the imperative has arisen for the dynamic collapse model to make quantitative predictions of the deformation path followed by peak-ring material during crater collapse. Here, we present analysis of the stress-strain path followed by material in the dynamic collapse model of peak-ring formation and compare the results to observed deformation from the Chicxulub peak ring.

\section{The Chicxulub Crater and the Dynamic Collapse Model}

The Chicxulub crater, located in the Yucatán peninsula of Mexico, is a 200-km-diameter impact structure (Gulick et al., 2008). The identification of the Chicxulub structure (Hildebrand et al., 1991; Penfield \& Camargo, 1981) was initially made on the basis of large-scale geophysical signatures: a large negative Bouguer gravity anomaly and magnetic anomalies; the structure's impact origin was confirmed by the identification of shock metamorphosed quartz in samples from within the crater structure (Hildebrand et al., 1991). The crater is buried, and the only surface expression of its presence is a ring of cenotes, water-filled sinkholes in the Cenozoic limestones, $70-85 \mathrm{~km}$ in radius.

Seismic reflection and refraction surveys were carried out at the site in order to resolve the crater and subcrater structure (Gulick et al., 2008; Morgan et al., 1997). The results of those surveys (Gulick et al., 2013, and references therein) indicated that the Chicxulub crater possesses: a topographic (inner) rim, 140-170 km in diameter, hereafter termed the "crater rim"; noncontinuous ring faults, external to the crater rim; one, the "outer" ring $200 \mathrm{~km}$ in diameter and a second, "exterior" ring that is up to $250 \mathrm{~km}$ in diameter. Additionally, the crater possesses an 80- to 90-km diameter peak ring, which rises up to $400 \mathrm{~m}$ above the crater floor, beneath which a strong, inwardly dipping reflector can be found. The peak ring and its inwardly dipping subsurface structure correspond to a low-velocity zone, $\sim 4 \mathrm{~km} / \mathrm{s}$. A ring-shaped gravity minimum within the crater at $\sim 35-\mathrm{km}$ radial distance suggests that the low-velocity zone, and thus, the peak-ring structure is composed of low density rocks. The crater possesses a terrace zone that extends inward from the crater rim, toward and beneath the peak ring, separated by the dipping reflector. Finally, the Moho is uplifted by $1.5-2 \mathrm{~km}$ beneath the crater center.

Results of the geophysical surveys at the Chicxulub structure motivated the initial numerical simulations of peak-ring formation by dynamic collapse (Collins et al., 2002) and provide important constraints on any model of peak-ring formation. The combination of geophysical constraints with numerical impact models suggest that the peak ring belongs to the paraautochtonous rocks within the crater, albeit possessing unusually low densities and seismic velocities. The structure has been drilled on several occasions, many of which were before the identification of the structure as an impact crater.

Investigating the mechanism of peak-ring formation was one of the primary aims of IODP-ICDP Expedition 364 (Morgan et al., 2017). The expedition recovered core between 505.42 and 1,363.05 mbsf (meters below sea floor) including the following: from 505.42-617.82 mbsf, carbonate-rich Palaeogene sedimentary rocks; from 617.82-750.25 mbsf, allochthonous impactites, predominantly fining-upward suevitic breccias (a polymict breccia containing crystallized or glassy clasts of impact melt) with impact melt rock at its base; and from 750.25-1363.05 mbsf, crystalline target rocks (Figure 1). The crystalline target rocks recovered during the expedition were predominantly granitic rocks, with occasional preimpact igneous dikes.

Initial analysis of the recovered core provided several constraints on the provenance of peak-ring material and the deformation that those rocks must have experienced during cratering. The occurrence of crystalline rocks at depths of only $750 \mathrm{mbsf}$ suggests that the crystalline rocks have been uplifted by at least $2.25 \mathrm{~km}$, such that rocks derived from beneath the approximately 3-km-thick Mesozoic sedimentary cover reached their final location in the peak ring. Additionally, the presence of abundant quartz Planar Deformation Features (PDFs) but the absence of diaplectic quartz glasses within the granitic target rocks indicate that the recovered paraautochthon, the shocked target rocks, experienced shock pressures from 10 to not more than $35 \mathrm{GPa}$ (Morgan et al., 2016). Moreover, the mechanisms of accommodating rock deformation, and the timing of those mechanisms, within the peak ring during cratering have been described by Riller et al. (2018). At the beginning of the cratering process, target rocks were pervasively fractured, followed sequentially by the formation of cataclasite zones, ultracataclasite zones, shear faults, the emplacement of fault breccias, 


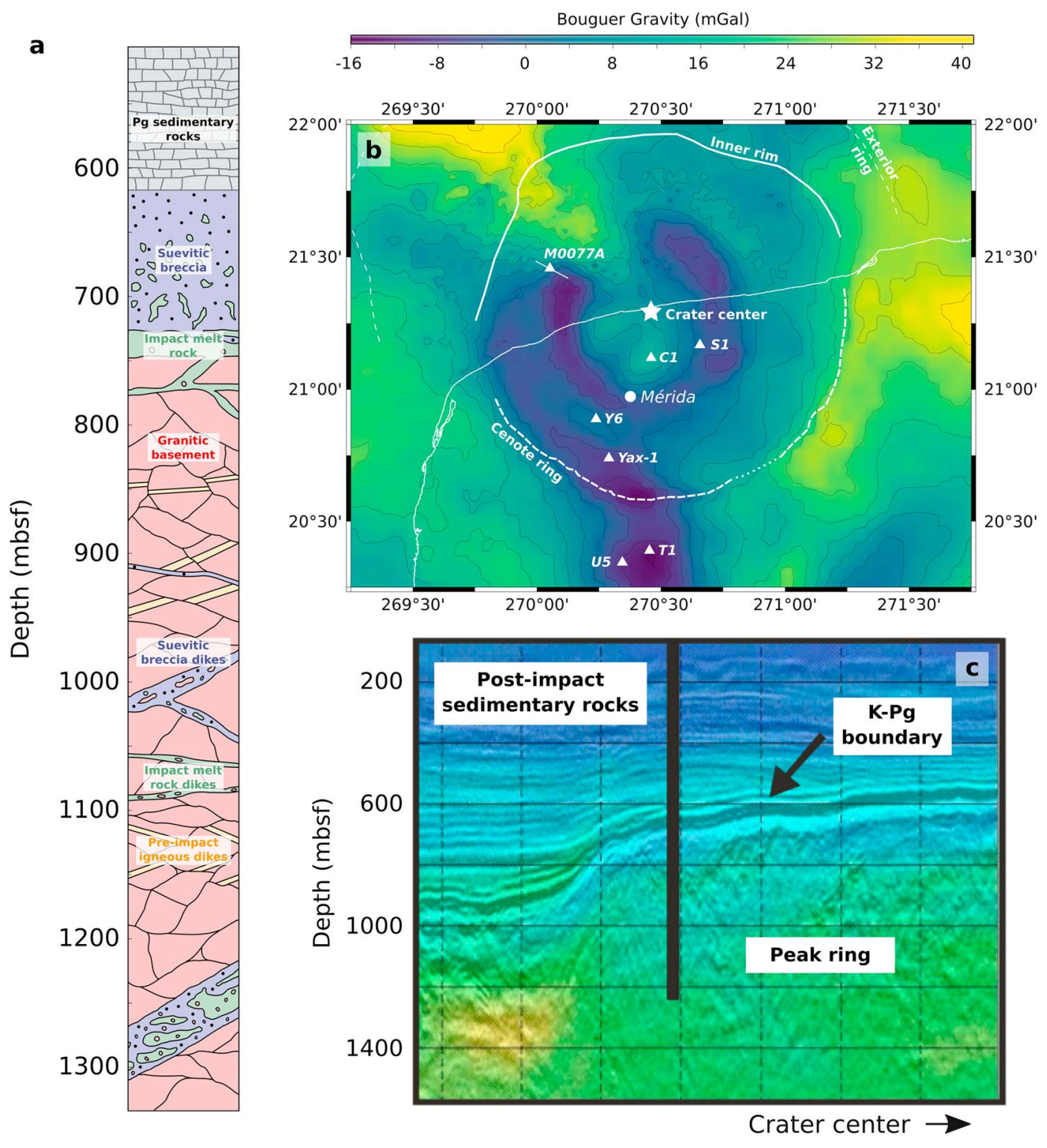

Figure 1. (a) Schematic stratigraphic log of Hole M0077A. The location of M0077A is indicated on subfigures, (b) a Bouguer gravity anomaly map of the crater, and (c) a radial seismic profile of the peak ring through the site location. Modified from Gulick et al. (2013) and Morgan et al. (2016).

impact breccias, and impact melts into dilatant fractures, and finally, the formation of brittle-ductile shear bands.

With this contribution, we aim to quantify the stress and strain histories of peak-ring material during cratering, constraining the timing, magnitude, and orientation of stress and strain. This aim will be addressed by the implementation of stress and strain tensorial analysis to the results of numerical impact simulations and the subsequent comparison with observed deformation from the Chicxulub peak ring.

\section{Numerical Modeling}

The formation of the Chicxulub impact structure was simulated using the iSALE shock physics code. iSALE is a multirheology, multimaterial code based on the SALE hydrocode (Amsden et al., 1980). Modifications to the original code have included an elastoplastic constitutive model, fragmentation models (Melosh et al., 1992), various equations of state (Ivanov et al., 1997), a porous compaction model (Wünnemann et al., 2006), and a dilatancy model (Collins, 2014). iSALE and its precursor codes, SALES-2 (Collins et al., 2002) and 
SALE-B (Ivanov, 2005), have been used to simulate the formation of the Chicxulub impact structure in previous studies (Collins et al., 2002, 2008; Ivanov, 2005; Morgan et al., 2016). Here, we present an updated model, including use of a dilatancy model (Collins, 2014) and updating previously used parameters in light of recent advances.

Computational improvements over recent years have permitted us to substantially increase the resolution of the Chicxulub model presented here. We use a resolution of 60 cells per impactor radius, which, with an impactor radius of $6 \mathrm{~km}$, results in cell widths of $100 \mathrm{~m}$. Previously published simulations of the Chicxulub have achieved cell widths of $200 \mathrm{~m}$ (Collins et al., 2008). Here, we have increased the resolution in order to facilitate as close a comparison as currently possible between the results of numerical simulations and the length of recovered impactites from Expedition $364(745.23 \mathrm{~m})$. Even so, it is worth noting that the whole length of the recovered core is encapsulated by only eight computational cells and that structural observations of the core are made on the centimeter-meter scale.

Impactor parameters in previous simulations of the Chicxulub impact event (e.g., Collins et al., 2008) have used impactor densities, diameters, and velocities of $2,670 \mathrm{~kg} / \mathrm{m}^{3}, 14 \mathrm{~km}$, and $12.0 \mathrm{~km} / \mathrm{s}$, respectively. In this study, we have made modified those parameters, where the impactor density, diameter, and velocity are $2,670 \mathrm{~kg} / \mathrm{m}^{3}, 12 \mathrm{~km}$, and $15.0 \mathrm{~km} / \mathrm{s}$, respectively. The cause of this modification is due to upward revision of the average asteroidal impactor velocity on Earth to $20.5 \mathrm{~km} / \mathrm{s}$ (Le Feuvre \& Wieczorek, 2011). Statistical probability indicates that vertical impacts are unlikely and that the most probable impact angle is $45^{\circ}$ (Shoemaker, 1962). Three-dimensional simulations are capable of modeling impactor obliquity; however, this significantly compromises the available resolution. Therefore, we use the iSALE-2D code and adjust the impactor velocity such that potential impactor obliquity is accounted for. It has been shown that transient cavity size scales with the vertical component of the impactor velocity (Chapman \& McKinnon, 1986; Elbeshausen et al., 2009). Consequently, we have adopted $15.0 \mathrm{~km} / \mathrm{s}$ as the impactor velocity, which is the vertical velocity component of an impactor traveling at $20.5 \mathrm{~km} / \mathrm{s}$ at $45^{\circ}$. As a consequence of the increase in impactor velocity in this simulation, the impactor diameter has been decreased, to $12 \mathrm{~km}$, from the value used in previous simulations (e.g., Collins et al., 2008), $14 \mathrm{~km}$, such that the impact energy (and, approximately, the transient cavity diameter) of the presented simulation is consistent with previous models. Nevertheless, we note that there are considerable uncertainties in the choice of impactor diameter. Primarily, this is a consequence of a trade-off between impactor parameters/transient cavity size and acoustic fluidization parameters in determining the final crater dimensions. Simulations were run using a variety of acoustic fluidization and impactor parameters, a comparison between the model presented here, previous models, and alternative models is presented within the supporting information (Figures S1 and S2 and Table S3). Ultimately, the stress-strain measurements presented here are qualitatively similar to the results of alternative models, provided that transient weakening from acoustic fluidization is sufficiently strong and long lasting to produce a peak-ring crater.

The thermodynamic behavior of the materials in the model is described by an equation of state (EoS). For each material, we used tables generated using the analytic EoS program (ANEOS, Thompson \& Lauson, 1974). A three-layer target was selected to replicate the conditions of the Yucatán platform at the time of impact. A 3-km layer of sedimentary rocks, using the calcite EoS (Pierazzo et al., 1998), overlies a 30-km layer of crystalline crustal rocks, using the granite EoS (Pierazzo et al., 1997), which overlies crystalline mantle rocks, using the dunite EoS (Benz et al., 1989).

The primary parameters that describe a material's yield strength are pressure, temperature, and material damage (Ivanov et al., 1997). Here, we use the shear failure constitutive model described by Collins et al. (2004) and do not use a tensile failure model. Instead, a negative pressure limit is set based on the intersection of the yield envelope with the pressure axis. Tensile failure was not considered in the models presented here because peak-ring material, the focus of this contribution, only ever experiences compressive principal stresses (e.g., Figure 6 in Ivanov et al., 1997). Constitutive model parameters for all materials were based on those used in previous models (Collins et al., 2008).

Gravitational collapse of the transient cavity is facilitated by the implementation of acoustic fluidization (Melosh, 1979) as a supplement to the constitutive model (Melosh, 1989; Melosh \& Ivanov, 1999). Here, we use the block model implementation of acoustic fluidization (Ivanov \& Kostuchenko, 1997). The result of this model is a rheology with a time-dependent yield strength and a constant effective kinematic viscosity, 
$\eta$. Acoustic energy within the material is assumed to decay exponentially, with decay time constant $T_{\mathrm{dec}}$, causing a gradual increase in strength as time progresses.

Dilatancy is the volume change observed in granular materials when they are subjected to shear deformations. The dilatancy model in iSALE is described by Collins (2014). In iSALE, the equation used to update the distension in cells undergoing shear deformation is as follows:

$$
\frac{\mathrm{d} \alpha}{\mathrm{d} t}=\alpha \beta \frac{\mathrm{d} \gamma_{p}}{\mathrm{~d} t},
$$

where $\alpha$ is the distension, which is defined as the ratio of the grain density to the bulk density, and $\frac{\rho_{s}}{\rho}$ (and can be defined as a function of porosity, $\frac{1}{1-\phi}$ ). $\beta$ is the dilatancy coefficient, which describes the material's tendency to gain volume upon plastic shear strain and is a function of pressure, temperature, and the preexisting dilatancy of the material (Equation (6) in Collins, 2014). The final term of equation (1) is the plastic shear strain rate; this value is determined by iSALE based on velocity gradients in the cell (see Collins, 2014). The dilatancy model is used for completeness and only has a significant effect on volume strain, without any noticeable effect on shear strain, or stress conditions for the material studied here.

A complete list of the parameters used in our simulation, including dilatancy model parameters, is shown in the supporting information (Tables $\mathrm{S} 1$ and $\mathrm{S} 2$ ).

\subsection{Stress and Strain During Impact Cratering}

Rocks undergo deformation during impact cratering. Deformation of a body is the transformation from its initial geometry to its final geometry by means of translation, rotation, and/or strain, which can be a distortion or a volume change. Translations and rotations are known as rigid body deformations, while distortions and volume changes are known as nonrigid body deformations. These deformations are variably complex to quantify by observation (Fossen, 2016; Ramsay \& Huber, 1983). Commonly, nonrigid body deformations are the easiest to observationally quantify. Consequently, providing quantitative predictions of deformation, separating translations, rotations, and strains, is of paramount importance to numerical impact simulations.

iSALE uses an Eulerian frame of reference; that is, properties, such as pressure, temperature, or stress, are saved at specific locations on a grid. A more useful frame of reference to consider when attempting to follow the material's path through property space is a Lagrangian reference frame, where individual material parcels, and their corresponding properties, are tracked. To accomplish this in iSALE, Lagrangian tracer particles are embedded within the mesh in the initial time step (e.g., Pierazzo et al., 1997), their locations then follow the material flow, and properties are saved at specific time steps. Here, tracers are advected through the grid based on the velocities of the Eulerian grid nodes (Davison et al., 2016; Pierazzo et al., 1997).

We quantify deformation during impact simulations by considering a 3-D Lagrangian pseudo-cell, that is, a "logical" cube of neighboring Lagrangian tracer particles. The three dimensions of the simulation are in a cylindrical coordinate system, corresponding to the radial direction, $r$, the vertical direction, $z$, and the azimuth, $\theta$. Thus, the pseudo-cell has an initially square cross section and is a toroidal sector in shape with eight nodes (Figure S3). By calculating the deformation gradient tensor for the pseudo-cell transformation and using the assumptions of infinitesimal strain theory, the infinitesimal strain and rotation tensors of the deformation between saved time steps can be derived. These saved time steps have an interval at least one order of magnitude greater than the interval between calculated time steps in the iSALE code. During analysis of the material of interest to this contribution, we found that saving time steps at a fine temporal scale is necessary during shock and decompression to accurately characterize deformation. Decreasing the interval between saved time steps beyond $25 \mathrm{~ms}$ produces no significant improvement on the results at the cost of unwieldy data file sizes; thus, we used an interval of $25 \mathrm{~ms}$ between saved time steps during shock and decompression. After shock and decompression, coarser temporal scales can be used while retaining accuracy. Here, we have used 2-s intervals between saved time steps for transient cavity formation and crater collapse, respectively.

iSALE calculates the stress tensor as part of its routine for each time step as an Eulerian field property. Consequently, saving the stress tensor as a Lagrangian tracer particle property simply requires that the tracer particle saves an interpolated value of the stress tensor within the cell that the tracer particle is within. In order to ensure exact correspondence between the stress tensor and the infinitesimal strain tensor, we linearly interpolate the values of the stress tensor within the Lagrangian pseudo-cell, to make the tensor 
pseudo-cell centered, and between saved time steps, to ensure that the saved stress tensor corresponds to the average stress required to cause the corresponding infinitesimal strain. A detailed description of how strain and stress tensors are acquired and used may be found in the supporting information, an application of descriptions by Fossen and Tikoff (1993), Tikoff and Fossen (1995), Allmendinger et al. (2012), and Fossen (2016).

Several issues arise from the use of our treatment to calculate strains and stresses in three dimensions. First, our interpolated treatment of stress and strain between saved time steps is effectively the result of summing deformations from many individual computational time steps; therefore, our analysis produces a smoothing effect on the results of the simulation. The interval between saved time steps was carefully chosen for each stage of the cratering process to reduce effects from temporal underresolution while maintaining computational efficiency. Second, due to the axisymmetry of iSALE-2D simulations, out-of-plane deformation is not well characterized; shear strains and stresses can only occur in the $r-z$ plane, and strain can never be localized in the $\theta$ direction, precluding the simulation of radially oriented faults. Nevertheless, owing to the radial movement of material, hoop strains (changes in length along the $\theta$ axis) can be calculated. Finally, axial symmetry forces the impact angle to be perpendicular to the target but real impacts are unlikely to occur at this angle. Impactor obliquity would cause changes to both the magnitude and timing of stresses and strains distributed around the crater, most strongly during the contact and compression and excavation stages of cratering. Nevertheless, we note that recent 3-D numerical simulations of peak-ring formation show that peak-ring material experiences similar shock magnitudes regardless of azimuth in all but the most oblique impacts (Collins et al., 2017). Together, this suggests that the stress-strain history of peak-ring material during shock in moderately and steeply inclined impacts should be similar at all azimuths and, by the time of crater collapse, our analysis of stress and strain derived from 2-D simulations should be appropriate for all but the most oblique large impact events.

\section{Results}

Lagrangian pseudo-cell analysis was used to examine the stress-strain paths of material within a simulation of the Chicxulub impact event. Within the paraautochthon of a large impact structure, rocks from the peak ring have experienced the most extreme deformation during crater modification. For this reason, and due to the recent IODP-ICDP drilling of the Chicxulub peak ring, the peak-ring materials will be focused upon specifically.

Here, the material that forms the peak-ring structure, termed here and in the following sections as "peak-ring material," is defined based on two criteria: First, peak-ring material must be solid. Melted material is distinguished by peak shock pressures >60 GPa. Second, previous work (e.g., Collins et al., 2002; Grieve et al., 1981; Morgan et al., 2016) suggests that peak-ring material derives from the collapse of an overheightened central uplift thrust atop the rim of the transient cavity. Consequently, peak-ring material can be defined as belonging to the flanks of the central uplift at the time of maximum uplift (Collins et al., 2017). All of the material defined in this way undergoes a similar stress-strain history (see supporting information); thus, these criteria constrain a volume of material representative of the geological structure of the peak ring, rather than a topographic definition. Furthermore, this material has an inwardly dipping basal contact consistent with seismic observations and provides a method that can be used to define peak-ring material in lower resolution and 3-D models, where it may be challenging to define the peak-ring material based on topographic details. For this Chicxulub simulation, maximum central uplift occurs at $\sim 180 \mathrm{~s}$, and we define that peak-ring material is any material above the plane that defines the base of the maximum central uplift and within the $15 \mathrm{~km}$ that are interior to the trough that surrounds the maximum central uplift. The location of the material that satisfies these two criteria, the peak-ring material, is shown on Figure 2 throughout the simulation.

Our results show that the peak-ring material originates from 8 - to $11-\mathrm{km}$ depth and 10 - to $25-\mathrm{km}$ radial distance (Figure 2a). From shock wave arrival to the end of transient cavity growth, the material moves outward, adjacent to and a part of, the transient cavity wall (Figure 2b). This material subsequently collapses inward (Figure 2c) and becomes entrained into the flank of the central uplift (Figure 2d). At this time, the central uplift is overheightened and collapses radially outward (Figure 2e), emplacing the peak-ring material on top of the collapsed transient cavity rim (Figure 2f). The results presented here will use a single Lagrangian pseudo-cell from within the center of the peak-ring material, which is representative of the 

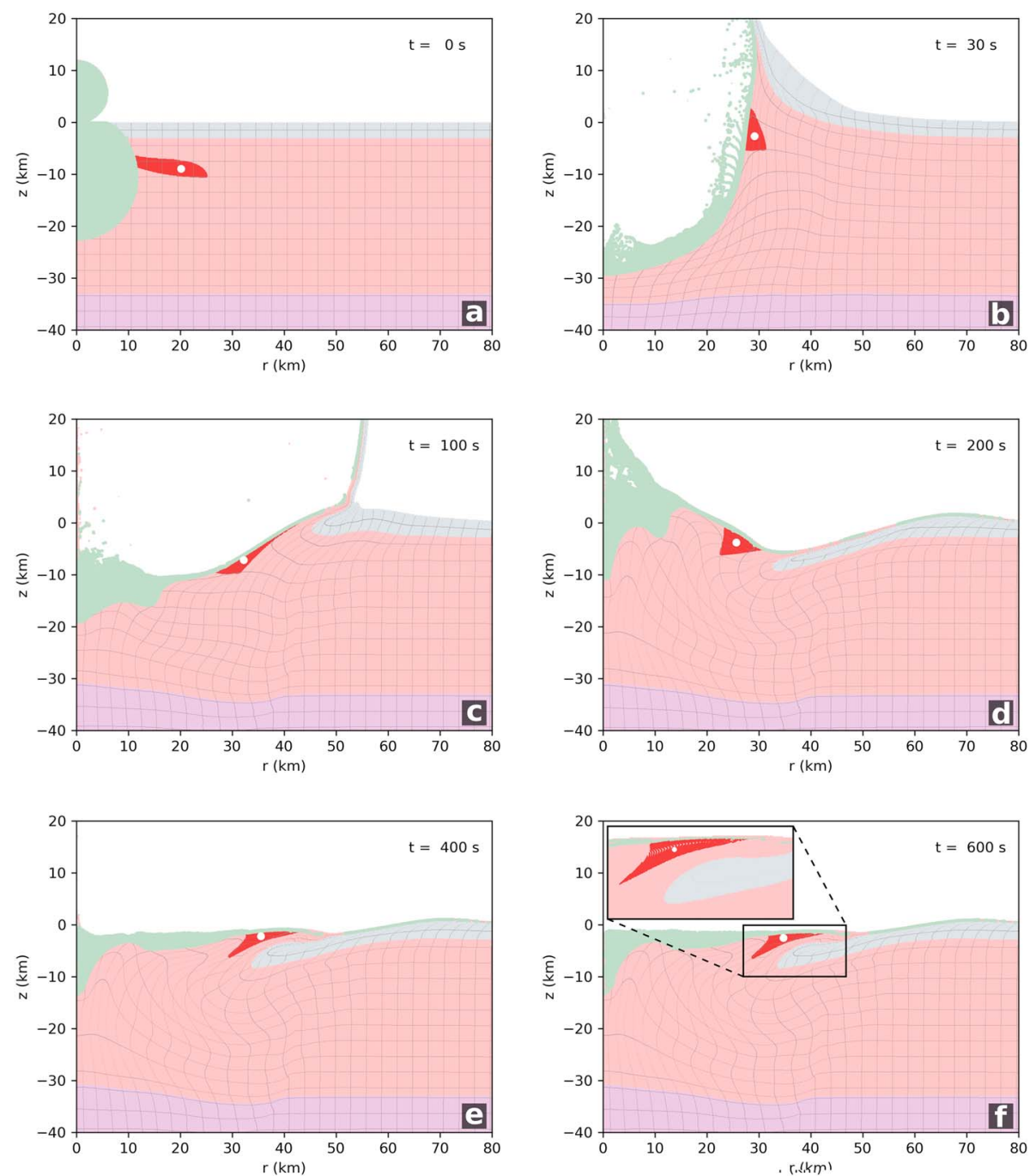

Figure 2. Selected time steps of the Chicxulub simulation presented here. The target is comprised of three layers: sedimentary rock (gray), granitic basement (pink), and mantle (purple). A grid of tracer particles is shown to highlight the target rock deformation. Additionally, in the first frame, (a), the provenance of impact melt and the peak-ring material are shown in green and red, respectively. The impact melt and peak-ring material is then tracked throughout the steps (b)-(f). The location of a single pseudo-cell (white) is shown throughout the simulation.

stress-strain history of the entire peak ring (see supporting information). This pseudo-cell originates from $20.2-\mathrm{km}$ radial distance and $8.95-\mathrm{km}$ depth and ends at $35.0-\mathrm{km}$ radial distance and $2.50-\mathrm{km}$ depth. The sequence of deformation of this cell will be described chronologically in the following sections.

\subsection{Deformation During Shock and Decompression}

The first stage of impact-related deformation to affect the peak-ring material is shock and decompression (Figure 3). Deformation is characterized by an initial, rapid horizontal compression of the material as it is shocked (Figure 3a), which results in a rapid reduction in the volume of the material (negative volumetric strains; Figure 3c) and a rapid increase in shear strain (Figure 3d). During these few milliseconds, strain rate reaches its maximum, $0.87 \mathrm{~s}^{-1}$ (Figure 3f). This value may be an underestimate due to the unavoidable effects of finite spatial and temporal resolution and the implementation of artificial viscosity in shock physics codes (see Anderson, 1987). As decompression occurs, the strain rate rapidly drops, volumetric strain increases and becomes positive (due to pressure release). Throughout the entire stage of deformation, there is a negligible amount of rotation of the material from its initial orientation (Figure 3e).

During shock and decompression, pressures and shear stresses rapidly increase (Figure 4). For the selected pseudo-cell, the arrival of the stress wave occurs at $2.10 \mathrm{~s}$. Most of the peak-ring material never experiences 

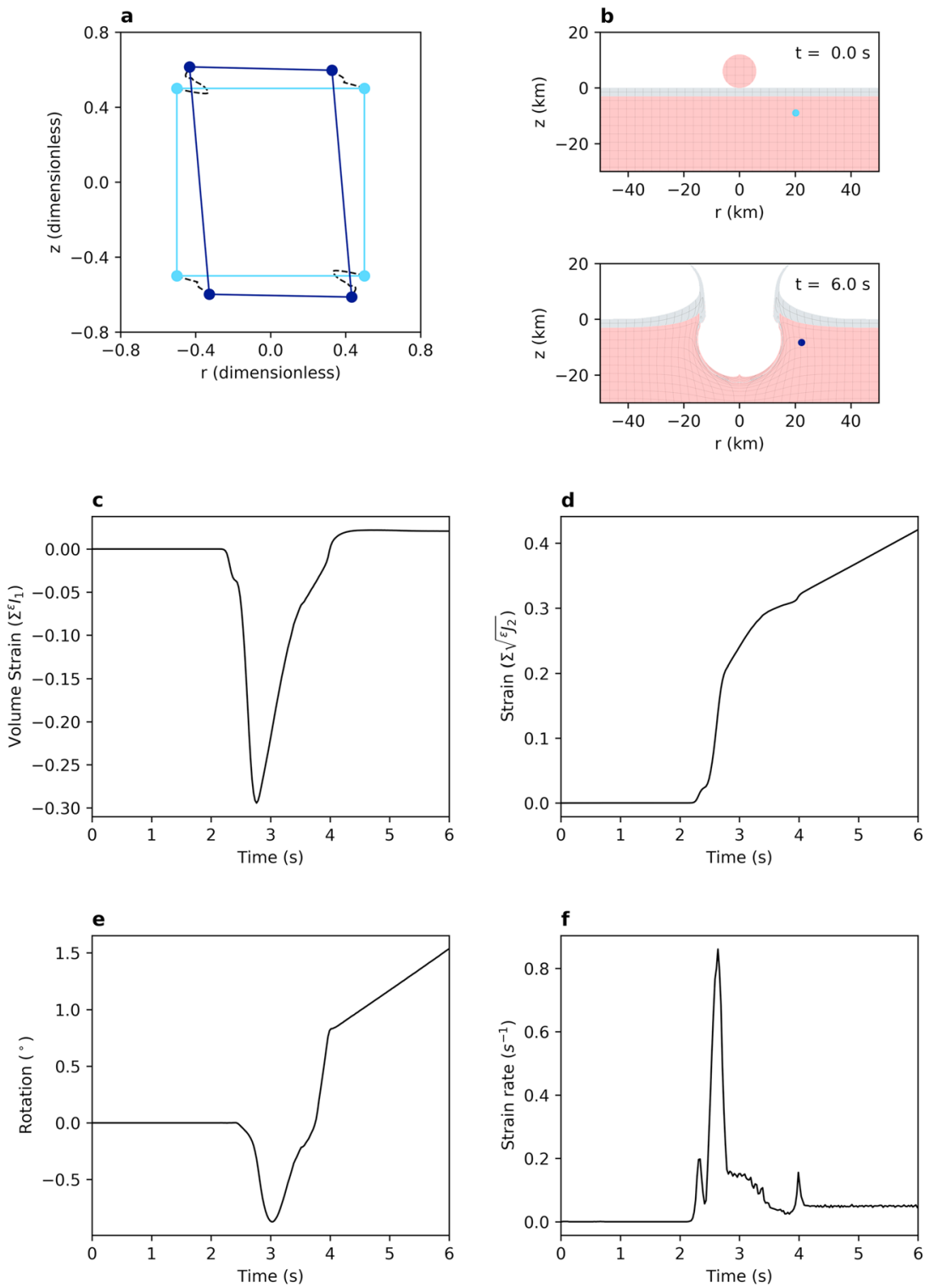

Figure 3. Strain path of the Lagrangian pseudo-cell during shock and decompression. (a) $r-z$ cross section of the pseudo-cell at $t=0.0 \mathrm{~s}$ (light blue) and $t=6.0 \mathrm{~s}$ (dark blue). The pathway of the individual tracers relative to each other through time is indicated by the dashed lines. (b) The initial $(t=0.0 \mathrm{~s})$ and postshock $(t=6.0 \mathrm{~s})$ arrangement of the simulation; see Figure 2. (c) The cumulative first strain invariant, ${ }^{\epsilon} I_{1}$. (d) The cumulative square root of the second deviatoric strain invariant, $\sqrt{{ }^{6} J_{2}}$. (e) Cumulative rotation (i.e., orientation) of the material. (f) Strain rate (i.e., the rate of change of cumulative $\sqrt{{ }^{E} J_{2}}$ with respect to time). Additional data may be found in the supporting information (Figure S4).

shock pressures greater than $40 \mathrm{GPa}$; therefore, the peak-ring material experiences shock metamorphism from a plastic wave with an elastic precursor. The stress wave exceeds the Hugoniot elastic limit (HEL; $3.56 \mathrm{GPa}$ for the granite strength properties used here) at $2.43 \mathrm{~s}$ where the maximum resolvable shear stress is $1.6 \mathrm{GPa}$. Pressures subsequently increase in the plastic wave up to $22.2 \mathrm{GPa}$ at $2.78 \mathrm{~s}$ and where the maximum resolvable shear stress is $2.0 \mathrm{GPa}$. At this moment of the peak shock condition, the rarefaction wave arrives and pressures begin to decrease. Nevertheless, maximum resolvable shear stresses increase until $3.13 \mathrm{~s}$, where the pressure is $15.5 \mathrm{GPa}$, and the maximum resolvable shear stress is $2.3 \mathrm{GPa}$. The cause of the increase in shear stress as pressure decreases in the wave is due to the rarefaction wave increasing the intermediate deviatoric principal stress, $s_{2}$, from tensile to compressive values (Figure 4). By $3.95 \mathrm{~s}$, the stress wave possesses a pressure less than the HEL. Beyond this time, the pressure and shear stresses do not return 

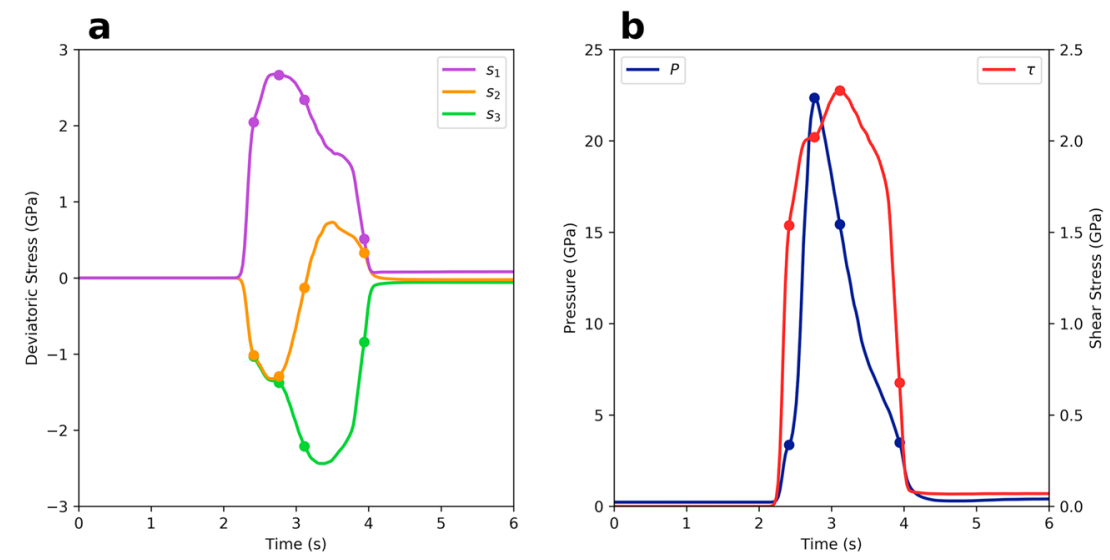

Figure 4. Stresses in a shock wave. (a) The deviatoric principal stress magnitudes within the pseudo-cell. (b) The shock pressure $(P)$ and maximum resolvable shear stress $\left(\tau=\frac{\sigma_{1}-\sigma_{3}}{2}\right)$ through time during shock and decompression. Points on the curves at $t=2.43,2.78,3.13$, and $3.95 \mathrm{~s}$ refer to the times at which the Hugoniot elastic limit is exceeded, maximum pressure is reached, maximum $\tau$ is reached, and when shock attenuates beneath the Hugoniot elastic limit, respectively.

to their preshock values; instead, they remain slightly higher as a consequence of the remnant postshock velocity imparted to the material.

Throughout shock and decompression, the orientations of the principal stresses change (Figure 5). The cause of principal stress rotation is due to the combined effects of refraction and, later, the interaction of the shock wave with the rarefaction wave. Initially, when the HEL is exceeded $(t=2.43 \mathrm{~s})$, the maximum principal stress within peak-ring material plunges inward $\left(15.2^{\circ}\right)$, while the minimum principal stress is near vertical and has a similar value to the intermediate principal stress oriented in the hoop direction. By the time of peak shock conditions ( $t=2.78 \mathrm{~s}$ ), the maximum principal stress has rotated to become near horizontal (3.2 $2^{\circ}$ inward), while the minimum principal stress becomes vertical. At this time, the intermediate principal stress has a similar magnitude to the minimum principal stress. By the time of maximum resolvable shear stress $(t=3.13 \mathrm{~s})$, the maximum principal stress orientation has continued to rotate and plunges outward $\left(31.5^{\circ}\right)$. At this time, the intermediate principal stress, $s_{2}$, is equal to the pressure (i.e., $s_{2}=0$ ), and remains in the hoop direction. By the time that the shock pressure decreases to the HEL $(t=3.95 \mathrm{~s})$, maximum principal stress is oriented steeply ( $51.6^{\circ}$ outward). At this time, the intermediate principal stress is nearly equal to the maximum principal stress.

The initial temperature of the pseudo-cell, prior to the passage of the shock wave, is $378 \mathrm{~K}$. During the passage of a shock wave, energy is deposited in the form of heat. As a consequence of shock and decompression, shock pressure and temperature conditions reach maximum values of $22.2 \mathrm{GPa}$ and $994 \mathrm{~K}$, respectively. Following decompression, the pseudo-cell arrives at a postshock temperature of $\sim 650 \mathrm{~K}$.

\subsection{Deformation During Transient Crater Formation}

The shape of a crater at the end of excavation and the beginning of modification is known as the transient crater (Dence et al., 1977; Melosh, 1989). This concept is important because the size of the transient crater is controlled by the kinetic energy and momentum of the impactor. Nevertheless, defining the transient crater of a large impact in numerical impact simulations is challenging because the transition from outwardly directed excavation flow to inwardly directed modification flow does not occur at the same time in all areas of the cavity. Thus, the transient crater is defined in numerical simulations as the cavity with the maximum volume (Elbeshausen et al., 2009). Maximum cavity volume occurs in the simulation presented here at $t=$ $30 \mathrm{~s}$, even though maximum cavity depth occurs at $t=20 \mathrm{~s}$ and rim growth continues beyond $t=30 \mathrm{~s}$.

Deformation during transient crater formation is characterized by continuing radial shortening as the transient cavity wall moves outward (Figure 6a) due to the remnant velocity of the rocks after shock, that is, the excavation flow field. Following strain rates approaching $10^{0} \mathrm{~s}^{-1}$ during shock and decompression, strain rates rapidly decrease to values of the order $10^{-2} \mathrm{~s}^{-1}$ and these strain rates only slightly decrease throughout transient crater formation (Figure 6f). The kinematic vorticity number during transient crater formation is always less than 0.3 , indicating that deformation is dominated by pure shear (Figure $6 \mathrm{~g}$ ). The preceding 
a
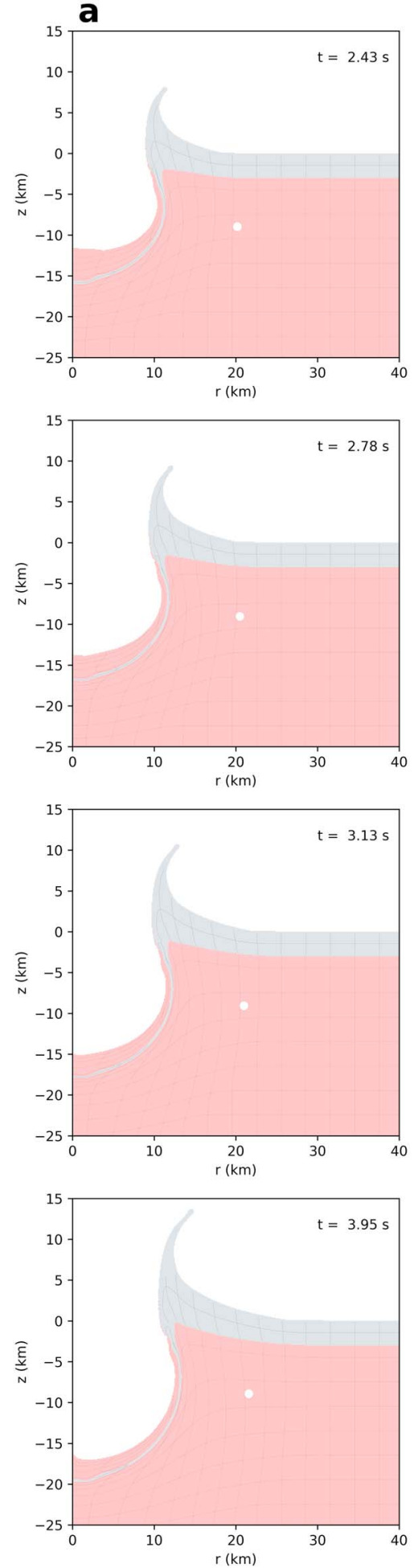

b
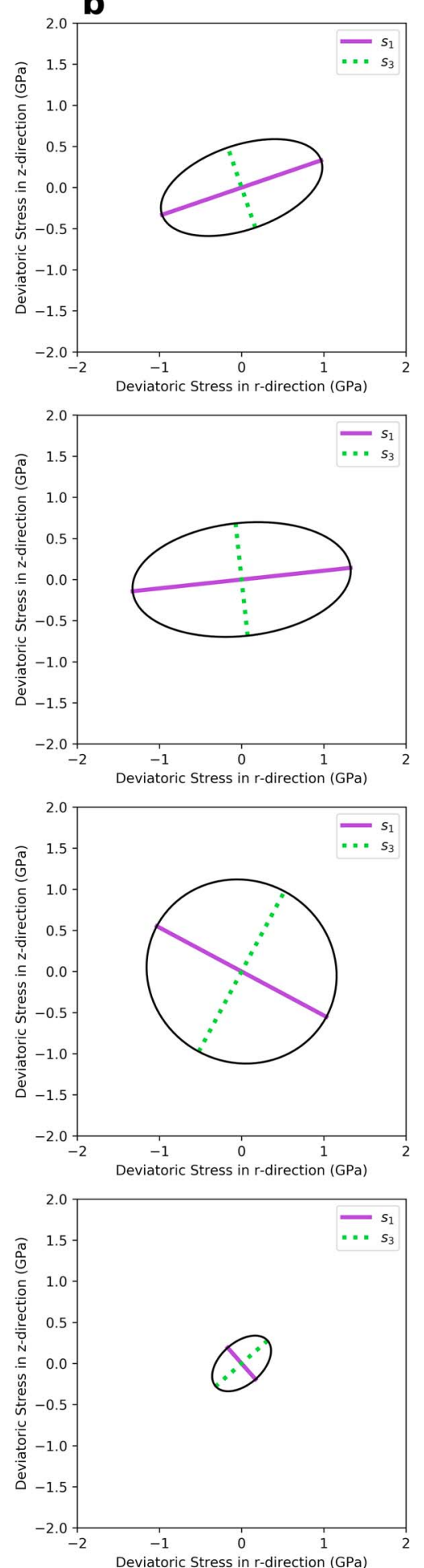
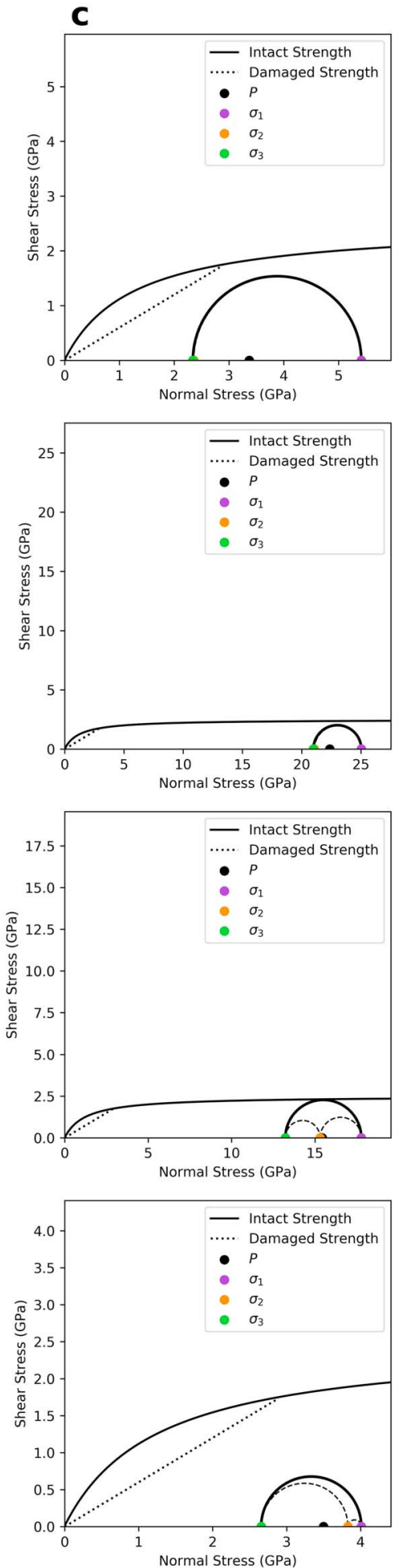

Figure 5. Stress orientations and magnitudes during shock and decompression. (a) Crater growth at time steps indicated in Figure 4 with location of the pseudo-cell indicated by the white marker. (b) $r$ - $z$ sectional deviatoric Lamé's stress ellipses at corresponding times, solid lines indicate compressive deviatoric stresses, while dashed lines indicate tensile deviatoric stresses. (c) Mohr's circle representation of the conditions of stress at corresponding times. Solid and dotted lines indicate the strength envelope of material at standard conditions, intact and damaged, respectively, these envelopes are drawn such that shear stress is measured by $\sqrt{{ }^{C} J_{2}}$, rather than $\frac{\sigma_{1}-\sigma_{3}}{2}$. Consequently, material is still at failure even though the Mohr circle may not be in contact with the strength envelopes. 
shock and decompression stage has kinematic vorticity numbers between 0.3 and 0.5 , and kinematic vorticity numbers increase toward the end of transient crater formation. Additionally, during this stage of deformation, the material initially rotates clockwise about the hoop direction by approximately $6^{\circ}$ before beginning to rotate counterclockwise from $25 \mathrm{~s}$ after impact (Figure 6e).

The orientation of stresses during transient crater formation remains consistent throughout and follows the excavation flow field (Figure 7). Initially $(t=6.0 \mathrm{~s}$ ), the pressure and deviatoric stresses are high and the maximum principal stress plunges gently outward $\left(8.8^{\circ}\right)$; these stresses rapidly decrease until $t=15 \mathrm{~s}$, after which, they remain comparatively constant. Nevertheless, the orientation of the maximum principal stress continues to rotate such that by $t=30 \mathrm{~s}$, the maximum principal stress plunges gently inward $\left(10.1^{\circ}\right)$. Throughout this stage of deformation, the intermediate deviatoric principal stress is tensile and is oriented in the hoop direction. Additionally, the proportional difference between $\sigma_{1}, \sigma_{2}$, and $\sigma_{3}$ remains constant. During this stage of cratering, transient strength reduction has no influence on deformation (Figure $7 \mathrm{c}$ ).

\subsection{Deformation During Crater Modification}

The stress-strain-time path during crater modification for peak-ring material is complex (Figure 8 ). Nevertheless, the deformation can be subdivided into five quantitatively distinct phases: rim growth $(t=30-90 \mathrm{~s})$, inward transport $(t=90-126 \mathrm{~s})$, central peak entrainment $(t=126-236 \mathrm{~s})$, outward transport (peak-ring emplacement $)(t=236-268 \mathrm{~s})$, and relaxation $(t=268-600 \mathrm{~s})$. The initial and final time steps of these phases are shown in Figure 8. Quantitative measures of the strain path are shown in Figure 9.

\subsubsection{Strain}

The first phase of crater modification from the perspective of peak-ring material, rim growth, is characterized by the deceleration of the material in the radial direction and the onset of significant clockwise (with respect to the hoop direction) rotation $\left(30^{\circ}\right)$; this rotation occurs as a consequence of the differential velocities of material above and beneath the peak-ring material. Beneath, material is beginning to collapse toward the crater center, while above, material is still being excavated radially outward. This differential velocity field also causes an increase in the relative amount of simple shear compared to pure shear; kinematic vorticity numbers increase from $\sim 0.3$ to $\sim 0.95$ (Figure $9 \mathrm{~b}$ ). Throughout this phase, the instantaneous principal strains all decrease in magnitude (Figure 9f), and strain rates decrease steadily from $2 \times 10^{-2}$ to $6 \times 10^{-3} \mathrm{~s}^{-1}$ (Figure 9a). The minimum principal strain $\left(e_{3}\right)$ remains perpendicular to the cavity wall, while the maximum principal strain $\left(e_{1}\right)$ is also contained within the $r-z$ plane.

The transition to the next phase of crater modification, inward transport, is characterized by the switching of the orientations of the minimum and intermediate principal strains (Figure 9f). The minimum principal strain, for the first time in the simulation, becomes oriented in the hoop direction; that is, the maximum shortening direction is concentric. This switch is a result of the inward transport of the peak-ring material as the transient crater wall collapses causing convergence of flow into the center of the crater. As the material flows inward, counterclockwise rotation continues (Figure 9c); however, strain rates are comparatively low (Figure 9a), and thus, this phase of modification is accompanied by comparatively small amounts of nonrigid body deformation (Figure 9).

The inward velocity experienced by the peak-ring material during inward transport ceases as the peak-ring material is entrained into the flank of the rising central uplift (Figure 2d). Central peak entrainment occurs as the central peak is rising (until $t=175 \mathrm{~s}$ ) and during the initial collapse of the overheightened central peak. During this phase, and slightly before, for the only time in the simulation after shock, strain rates increase (Figure 9a), reaching and maintaining rates of $10^{-2} \mathrm{~s}^{-1}$. Additionally, counterclockwise rotation of the peak-ring material continues until slightly after the central peak reaches its maximum height. At this time, the peak-ring material has reached a total rotation of approximately $90^{\circ}$ (Figure 9c). Additionally, while the central uplift builds, the maximum principal strain is oriented subvertically, while the minimum principal strain (maximum shortening) is oriented subhorizontally. Later, at the time of maximum central uplift, when the material finally ceases all inward movement and begins to move outward, the material and the principal strains begin to rotate clockwise (about the hoop direction; Figure 9c). By the end of the deformation phase, the minimum principal strain plunges inward $\left(23.4^{\circ}\right)$, parallel to the direction in which the peak ring is emplaced. The onset of the central peak collapse also causes an increase in the kinematic vorticity number from 0.1 to 0.9 (Figure $9 b$ ). 

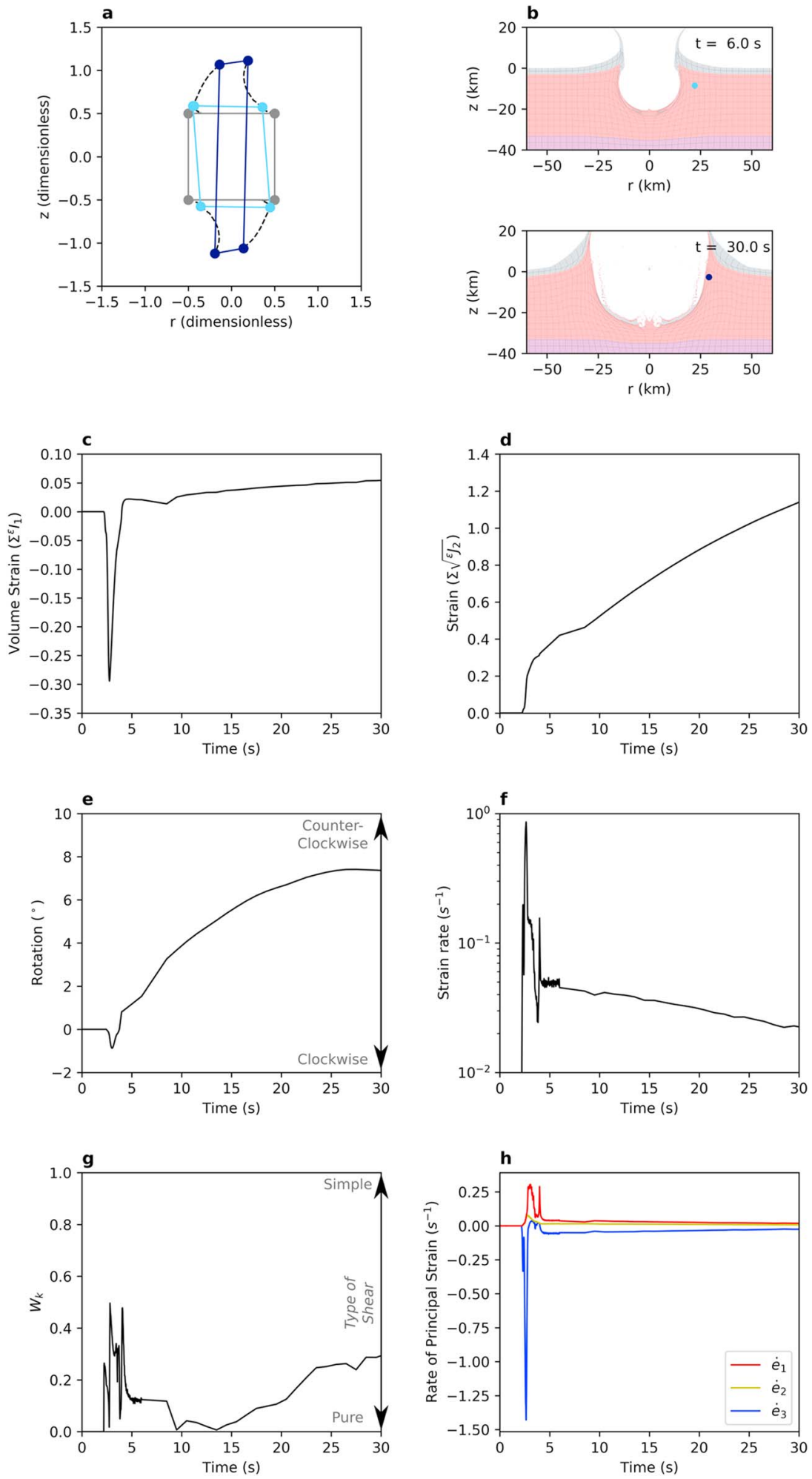

Figure 6. Strain path of the Lagrangian pseudo-cell during transient crater formation. (a) The $r-z$ cross section of the pseudo-cell at $t=6.0 \mathrm{~s}$ (light blue), $t=30.0 \mathrm{~s}$ (dark blue), and the original pseudo-cell at $t=0.0 \mathrm{~s}$ (gray). The pathway of the individual tracers relative to each other through time is indicated by the dashed lines. (b) The postshock $(t=6.0 \mathrm{~s})$ and transient crater $(t=30.0 \mathrm{~s})$ arrangement of the simulation; see Figure 2, (c) the cumulative first strain invariant, ${ }^{\epsilon} I_{1}$, (d) the cumulative second deviatoric strain invariant ${ }^{\epsilon} J_{2}$, (e) cumulative rotation (i.e., orientation) of the material, (f) strain rate (i.e., the rate of change of cumulative ${ }^{\epsilon} J_{2}$ with respect to time), (g) kinematic vorticity number, and (h) rates of principal strain through time. 
a

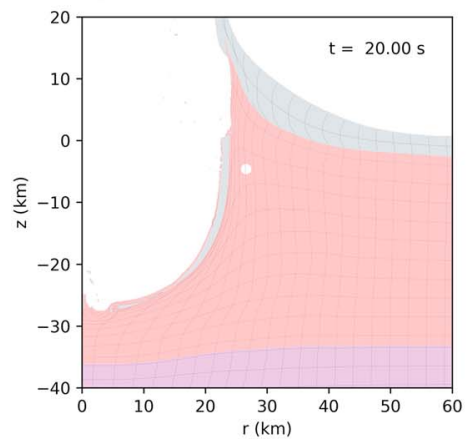

b

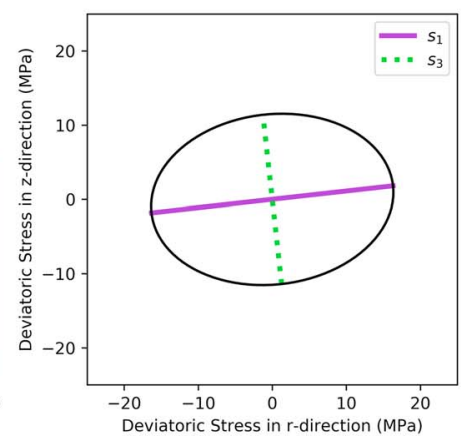

C

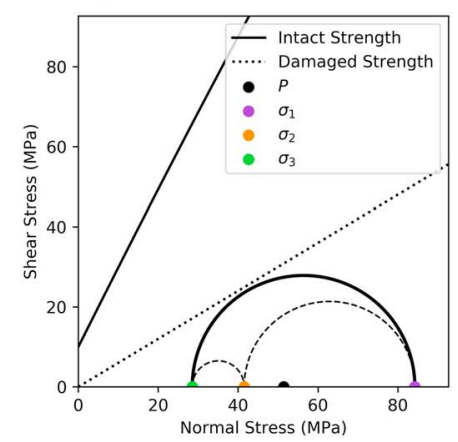

Figure 7. Stress orientation and magnitude during transient cavity growth. (a) Crater shape at $t=20 \mathrm{~s}$, with the location of the pseudo-cell indicated by the white marker. (b) Major and minor axes of the $r-z$ cross section of the deviatoric Lamé's stress ellipsoid, solid lines indicate compressive deviatoric stresses, while dashed lines indicate tensile deviatoric stresses. (c) Mohr's circle representation of the conditions of stress. Solid and dotted lines indicate the strength envelope of material at standard conditions, intact and damaged, respectively.

The transition from the central peak entrainment phase to the outward transport phase is marked by a rapid decrease in strain rate, from $10^{-2}$ to $10^{-3} \mathrm{~s}^{-1}$ (Figure 9a) and a change in the orientation of the principal strain axes (Figure 9f), whereby the now outwardly directed velocity of the material causes maximum principal extension in the hoop direction; this is the only time in the simulation where the maximum instantaneous stretch is in the hoop direction.

As the peak-ring material is emplaced outward, its radial velocity gradually decreases and the peak ring comes, on average to rest. After this occurs, the peak-ring material gradually relaxes and flattens; this phase of deformation, relaxation, occurs at comparatively small strain rates, declining from $10^{-3}$ to $10^{-5} \mathrm{~s}^{-1}$ (Figure 9a). By the end of the relaxation phase of crater modification, the material has undergone significant volumetric expansion (volume strain $=0.0338$ ), almost exclusively due to the effect of accumulated distension from the dilatancy model (Figure 9d).

The five phases of crater modification are marked by distinctly different strain states (Figure 10). The first phase, rim growth, and the contact and excavation stage produce oblate strain ellipsoids (flattening). The inward transport phase is marked by a prolate strain ellipsoid (constriction). The remaining phases of modification occur under near plane strain conditions, progressing from slightly constrictional to slightly flattening strains as time continues. This indicates that peak-ring rocks deformed during the earliest stages of cratering should have developed planar fabrics (S-tectonites), while deformation structures developed during later cratering phases should develop some linear fabrics (L-tectonites, or more realistically LS-tectonites).

\subsubsection{Stress}

During these phases of deformation, the peak-ring material experiences a sequence of stress states as complex as, and related to, the strain path that the material follows. Figure 11 shows the history of deviatoric principal stresses and pressure during the first four phases and into the final phase of the crater modification stage and Figure 12 shows representative sectional deviatoric Lamé's stress ellipses and Mohr's circle diagrams for each of the five phases of crater modification.

During the earliest phase of crater modification, rim growth, the peak-ring material experiences pressures from 5-25 MPa and shear stresses of $\sim 5-10 \mathrm{MPa}$ (Figure 11b). During this phase, the maximum principal stress orientation plunges inward (Figure 12a), parallel to the cavity wall; consequently, it rotates from steeply to shallowly inclined as the crater rim continues to grow.

Through the rim growth phase, the intermediate principal stress, which is oriented in the hoop direction, increases until, as the inward transport phase begins, the hoop stress exceeds the wall-parallel stress (Figures 11a and 12b). This occurs as a result of the inward convergence of the peak-ring material. During this phase, as the material converges into the building central peak, pressures and shear stresses increase to in excess of 50 and $15 \mathrm{MPa}$, respectively (Figure 11b).

As the inward transport of material meets increasing resistance against the rising central uplift during central peak entrainment, the radial, wall-parallel stress begins to exceed the hoop stress (Figure 12c). 
Shock and Excavation
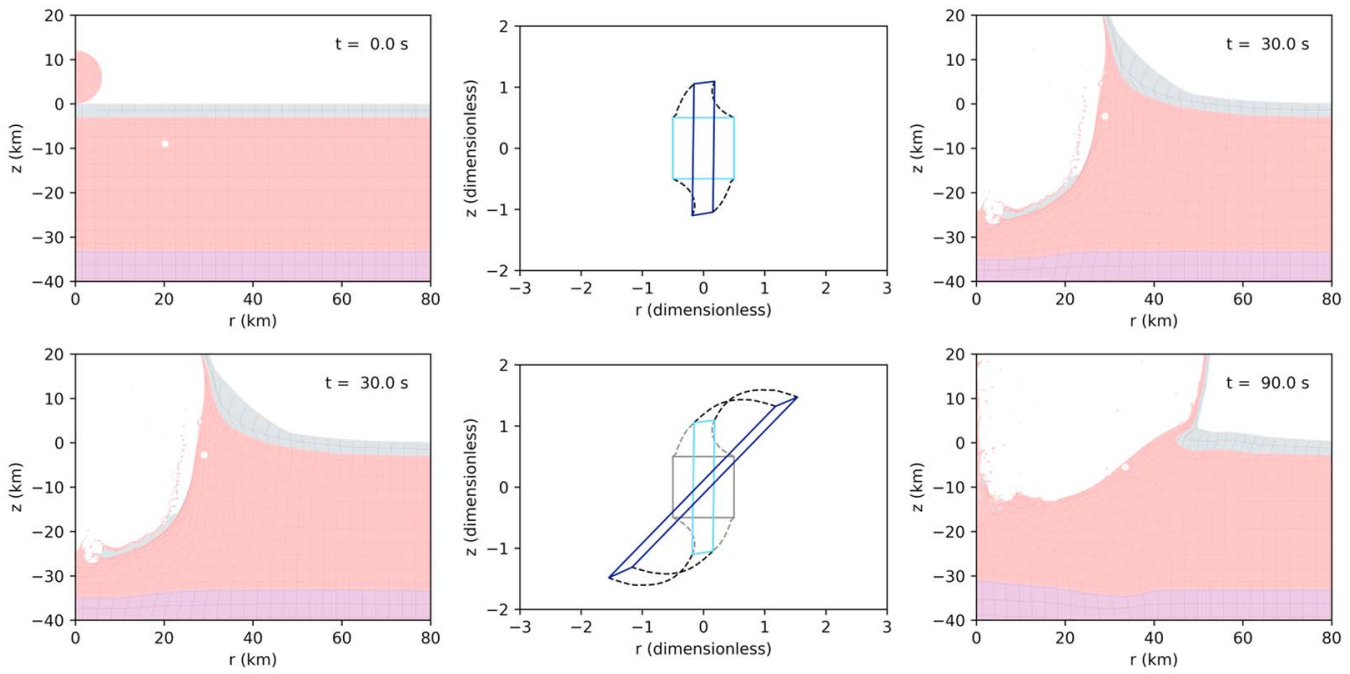

Rim Growth

Inward Transport

\section{Central Peak} Entrainment
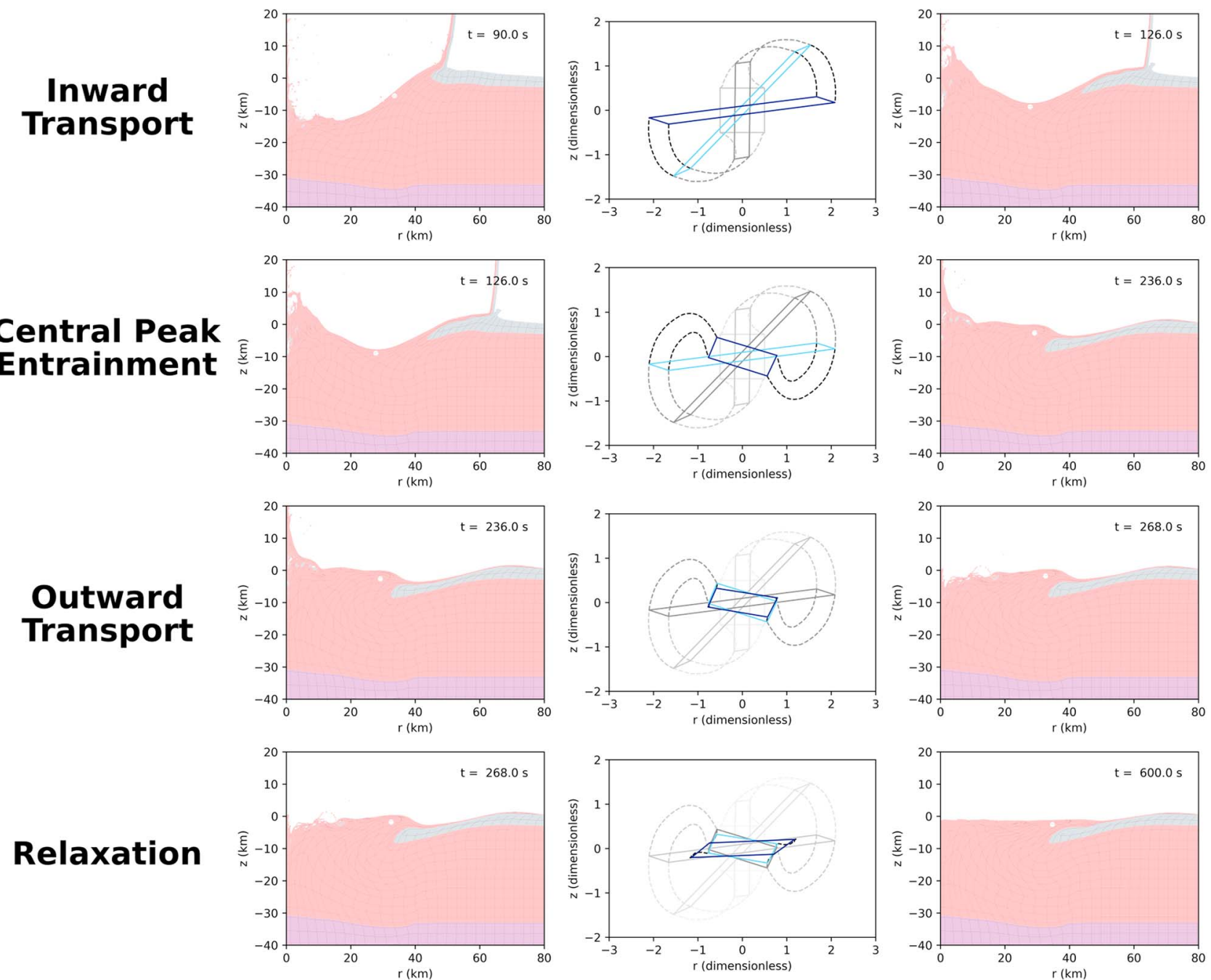

Figure 8. Strain phases during modification. Each row shows the first and last arrangement of the crater with the deformation of the indicated Lagrangian pseudo-cell. 

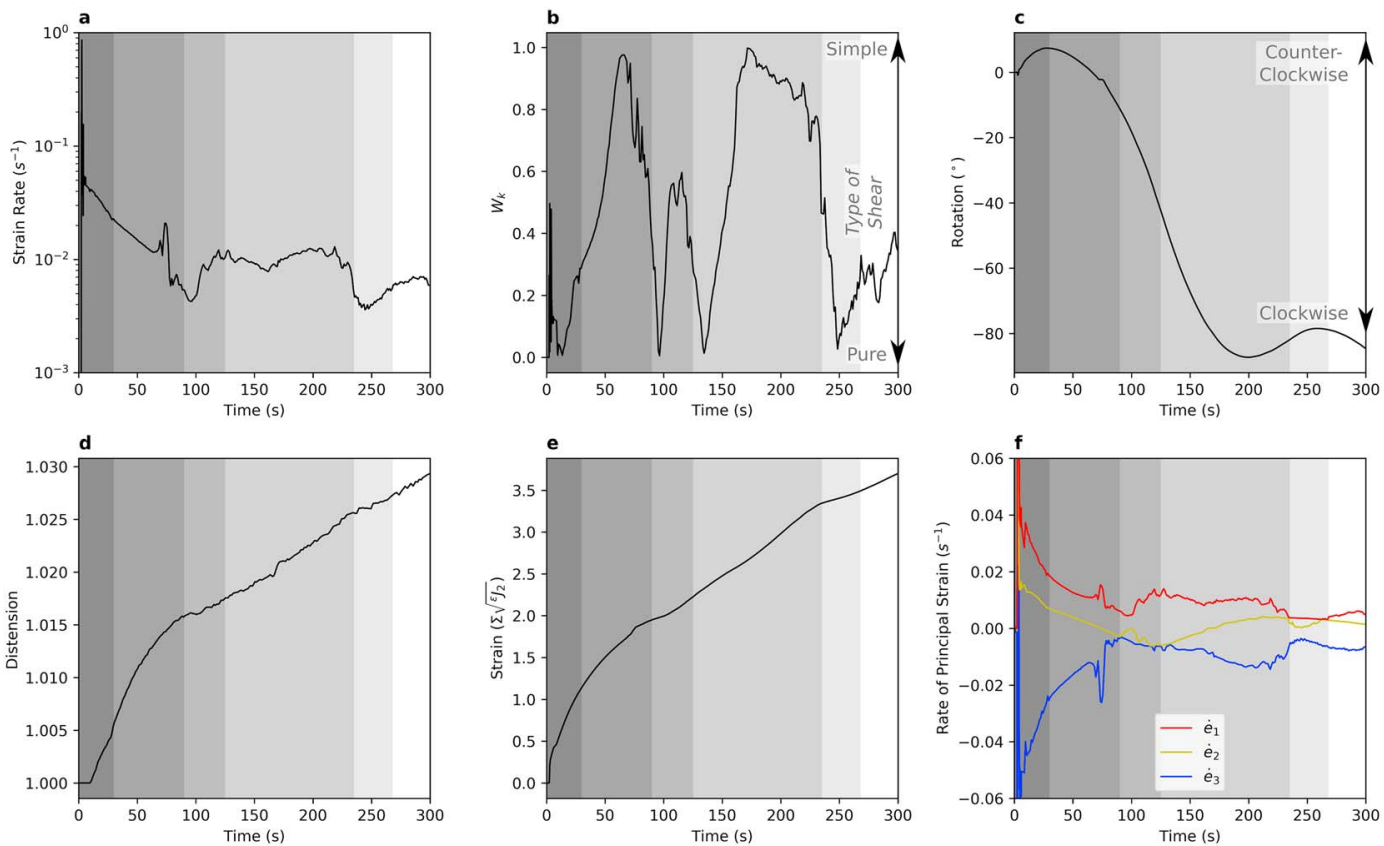

Figure 9. Quantification of strain during the phases of crater modification, the duration of each phase is indicated by the gray highlighting beneath the plots. Individual plots show: (a) strain rate, (b) kinematic vorticity number, (c) cumulative material rotation (i.e., orientation), (d) distension, (e) total deviatoric strain, calculated as the sum of $\sqrt{{ }^{C} J_{2}}$, and (f) rates of principal strain through time. Additional data may be found in the supporting information (Figure S5).

Meanwhile, the minimum deviatoric principal stress decreases causing large shear stresses during the central peak entrainment phase. Pressure in the peak-ring material during entrainment reaches up to nearly $100 \mathrm{MPa}$ (Figure 11b). During this phase, the maximum principal stress orientation rotates from plunging gently outward, through horizontal to plunging inward until the central uplift reaches its maximum height

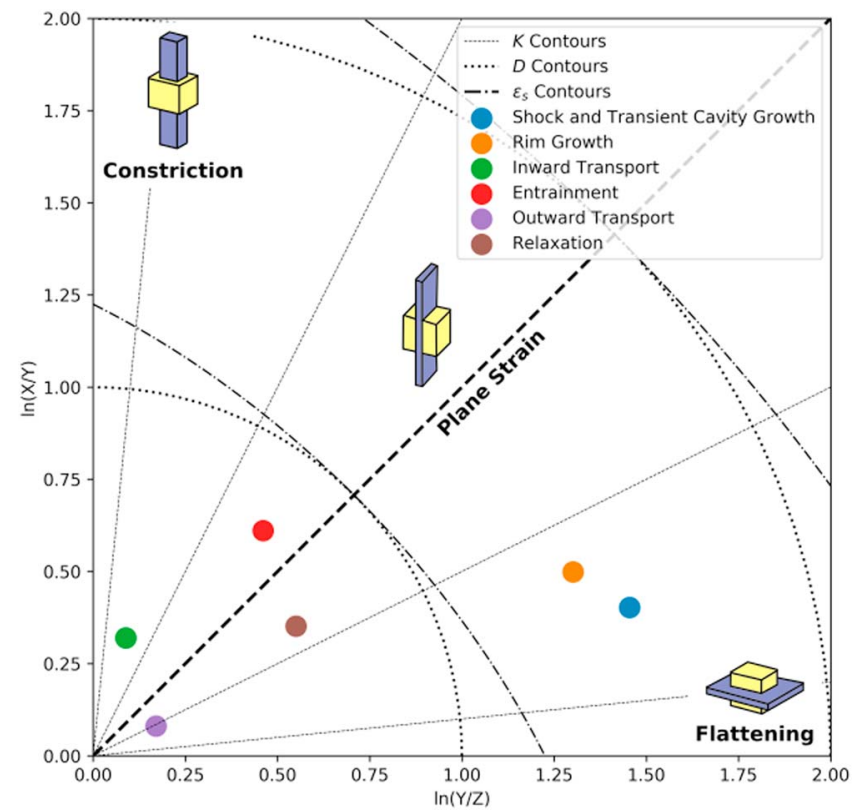

Figure 10. Flinn-Ramsay diagram of strain ellipsoids corresponding to each phase of peak-ring formation. K-numbers and D-numbers/ octahedral shear strain $\left(\varepsilon_{s}\right)$, which respectively describe the shape of the strain ellipsoid and the magnitude of strain, are contoured. 
a

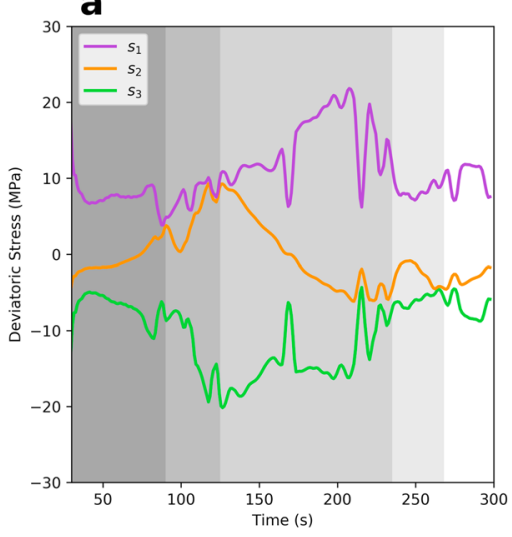

b

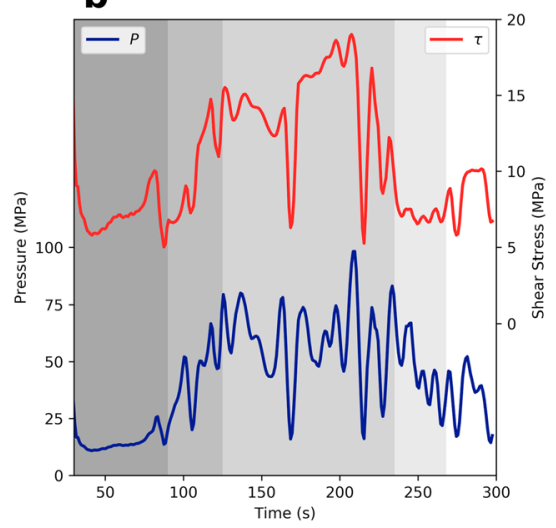

Figure 11. Stress magnitudes and pressure through time during crater modification, modification phases are highlighted as gray areas beneath: (a) principal deviatoric stress magnitudes and (b) pressure and maximum resolvable shear stress.

at $t=180 \mathrm{~s}$. Whereupon, the maximum principal stress remains in the same orientation as the central uplift begins to collapse (Figure 12c).

As the peak-ring material moves outward during the collapse of the central peak, the hoop stress, which is intermediate during central peak entrainment, continually decreases and becomes the minimum principal stress as the outward transport phase begins (Figures 11a and 12d). During this phase, the maximum principal stress plunges inward. This orientation gradually becomes less steep as the peak ring is emplaced; simultaneously, pressures in the peak-ring material gradually decrease as the peak ring loses height due to the hoop extension.

The relaxation phase of crater modification occurs as the stress state of the rocks returns to normal lithostatic conditions. The beginning of this phase is marked by the hoop stress becoming intermediate. As this phase continues, the maximum principal stress rotates to become vertical, that is, becomes entirely composed of the lithostatic stress (Figure 12e). During this phase, all but the most superficial material of the peak ring cease to move.

\section{Comparison to Observations From the Chicxulub Peak Ring}

Observations of impact-related deformation experienced by peak-ring material in the Chicxulub impact structure have been presented by Riller et al. (2018). Alongside shock deformation, evident by shatter cones, PDFs, and planar fractures in quartz and feldspars, severe structural modification is evident by brittle and ductile deformation structures. Most importantly, it is possible to determine the relative timing of the various types of deformation.

The first impact-related deformation to occur to the target rocks was shock metamorphism and pervasive fracturing at the grain scale. The fragmented geometry of the pervasively fractured target rock was then truncated by cataclasites and ultracataclasites. These cataclasites are spaced every few meters and occasionally crosscut each other. The cataclasites and ultracataclasites are, in turn, consistently offset by striated fault surfaces and millimeter-wide shear faults. Six hundred two striated fault surfaces were recorded in the core, some of which can be found within clasts of target rock within impact melt rock dikes and suevitic breccia dikes. These dikes are devoid of cataclasites and shear faults; however, they do contain abundant evidence of ductile strain. Meanwhile, target rocks within a zone of abundant breccia dikes and melt rock dikes from 1,220-1,316 mbsf are commonly deformed by brittle-ductile shear bands, which displace cataclasites and the contacts of melt rock dikes and breccia dikes. These ductile and brittle-ductile structures always indicate a normal shear sense.

Thus, in summary, a sequence of deformation experienced by peak-ring rocks during cratering can be defined: first, shock deformation and pervasive fracturing (Figures 13a and 13b), followed by the formation of cataclasites and ultracataclasites (Figures 13c and 13d), striated faults and shear faults (Figures 13d and 13e), the emplacement of breccia and impact melt into dilatant fractures (Figures 13e and 13f), and finally, 
a) Rim Growth $\mathbf{t}=60 \mathrm{~s}$

\section{c) Central Peak Entrainment $t=180 \mathrm{~s}$}

\section{e) Relaxation $\mathbf{t}=\mathbf{4 5 0} \mathrm{s}$}
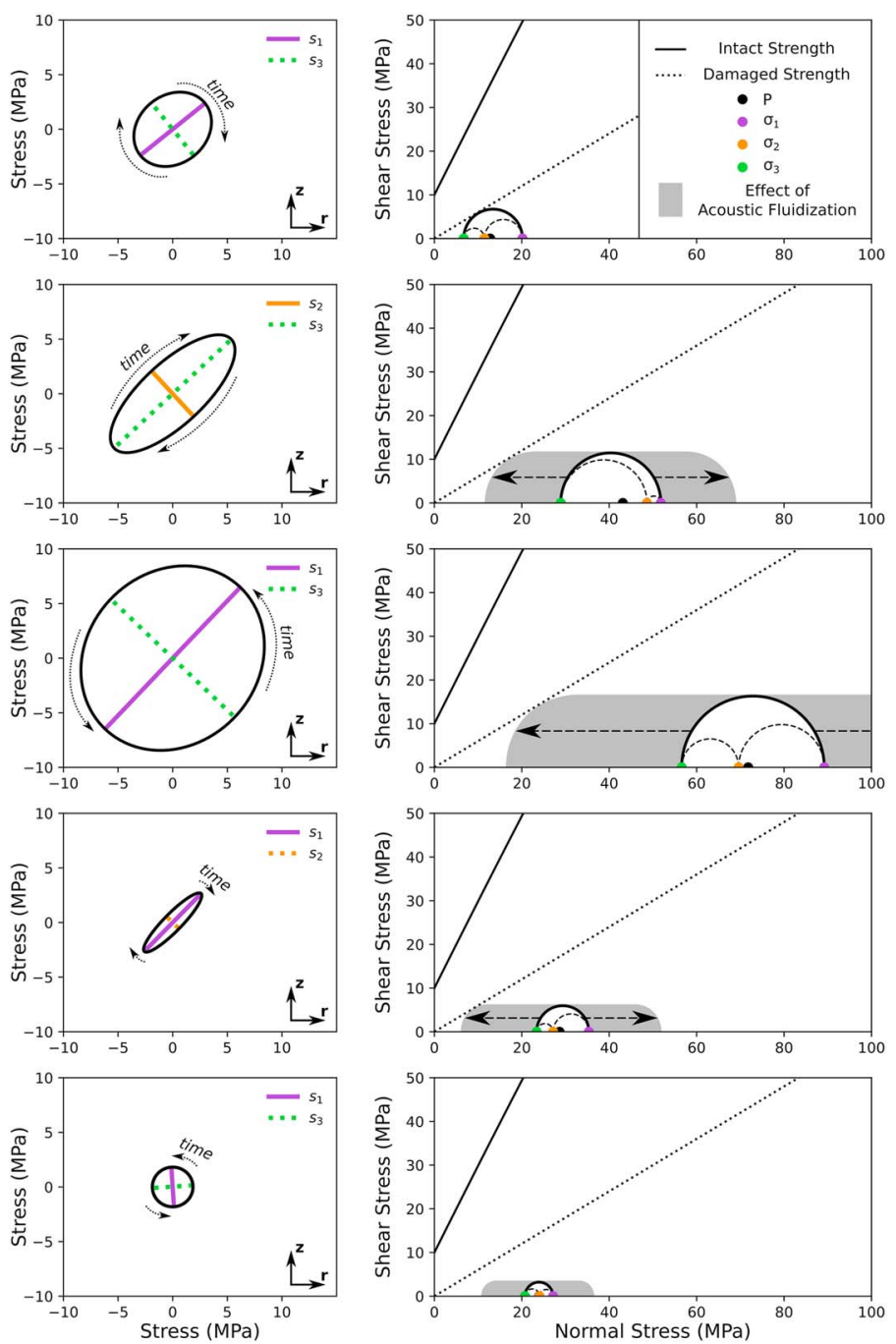

Figure 12. Sectional deviatoric Lamé's stress ellipses and Mohr's circle diagrams through the phases of crater modification. Rotation of the largest principal stress in the $r-z$ sectional stress ellipses through time is indicated, while the effect of acoustic fluidization is demonstrated on the Mohr's circle diagrams. The Mohr's circle diagrams drawn here are the average stress values over the calculated saved time interval, acoustic fluidization supposes that high-frequency oscillations may reduce, or increase, pressure about the average, and thus, rock failure may be facilitated when the pressure drops sufficiently that the Mohr's circle intersects the failure envelope. The gray envelopes schematically indicate the areas that the Mohr's circle passes through during acoustic vibrations.

the formation of brittle-ductile and ductile shear bands (Figure 13f). It shall now be demonstrated how these observations are consistent with quantitative results derived from numerical simulations.

\subsection{Pervasive Fracturing}

The controls of fault and fracture formation under compressional rock failure is a complex subject (Ramesh et al., 2015); nevertheless, the length scale at which faults and fractures form is controlled by strain, strain rate, and the speed at which fractures propagate (Melosh, 2005). Given a fixed amount of strain, high strain rates cause more closely spaced fractures than low strain rates. The cause of this behavior is that fractures cannot be longer than the distance that sound travels in the time that deformation occurs in. Consequently, the rapid, and predominantly pure shear deformation during shock and decompression at strain rates near to $10^{0} \mathrm{~s}^{-1}$, is expected to be the cause of pervasive fractures at the subgrain scale.

The likelihood that fractures occur on small length scales during shock and decompression, can be examined quantitatively by considering the compressional fragmentation model presented by Melosh et al. (2017), adapted from the tensional fragmentation model of Grady and Kipp (1980), where modal fracture spacing, $l$, is related to deviatoric strain, $\epsilon$ by the following: 

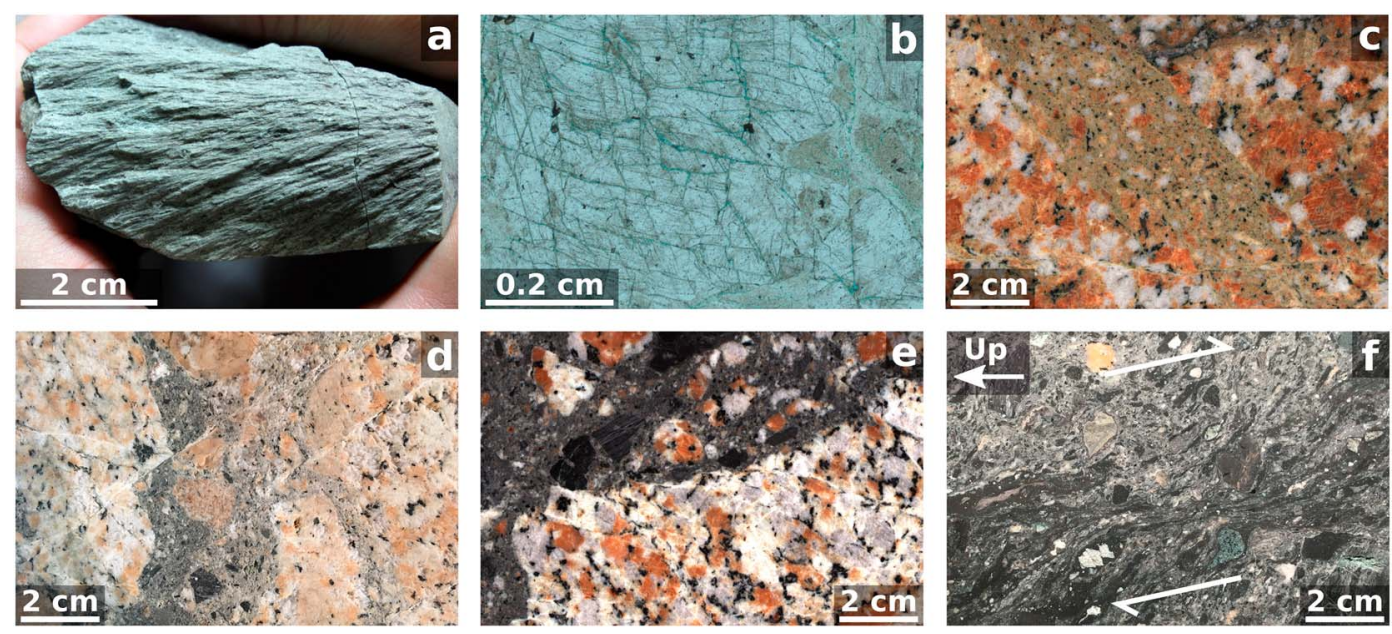

Figure 13. Sequence of deformation in Hole M0077A described in detail by Riller et al. (2018). (a) Shatter cone fragment from a breccia clast (708.50 mbsf; Morgan et al., 2016). (b) Plane-polarized transmitted light image of pervasive subgrain-scale fracturing in quartz with planar fractures and planar deformation features, pore spaces are filled with blue-dyed epoxy (1,076.15 mbsf). (c) Cataclasite (925.74 mbsf). (d) Cataclasite truncated by shear faults (1,255.54 mbsf). (e) Shear-faulted granite as clast within melt-bearing breccia (1,281.48 mbsf). (f) Ductile shear structure in melt-bearing breccia with normal shear sense displacement (white half-arrows; 1,289.64 mbsf).

$$
l=4\left[\frac{(m+1)(m+3)^{4}}{8 \pi k(m+2)^{5}}\right]^{1 / 3} \epsilon^{-m / 3}
$$

where $m$ and $k$ are the parameters that describe the Wiebull distribution of available flaws for fracture nucleation, $N=k e^{m}$. During shear failure, these parameters have values of $m=\frac{3}{2}$ and $k \approx 2.6 \times 10^{9} \mathrm{~m}^{-3}$ (Melosh et al., 2017; Ramesh et al., 2015). Using these values, and a value of $\epsilon$ equal to the cumulative deviatoric shear strain during shock $(\sim 0.3$; Figure $3 \mathrm{~d})$, the fracture spacing for the peak-ring rocks, $l=0.23 \mathrm{~cm}$. This value is similar to the spacing of the subgrain-scale fractures in the granitic target rocks (Figure 13b). Despite the pervasive fracturing that occurs during this stage of crater formation, it is not necessary that the material gains volume by dilatancy. Pressures are extremely high during this stage; therefore, fractures will not distend.

\subsection{Cataclasites and Ultracataclasites}

Following shock and decompression, during crater excavation, the material continues to deform by predominantly pure shear and is horizontally compressed (Figures $8 \mathrm{a}$ and $9 \mathrm{~b}$ ). Consequently, the deformation style during this stage of crater formation is not expected to be any different to that during shock and decompression. The low pressure and high strains during excavation are likely to cause the shock-formed fractures to dilate and introduce distension to the rocks. Additionally, as the strain rates are an order of magnitude lower (Figure 9a), displacement is likely to localize onto more widely spaced shock-formed fractures.

Toward the end of excavation and into the rim growth phase of crater modification, deformation becomes increasingly dominated by simple shear (Figure 9b). This change in the type of shear is likely to mark a change in deformation style, from pervasive fracture networks, brittlely accommodating a pure shear displacement field, to subparallel faults capable of accommodating a simple shear displacement field. Importantly, at the microscopic scale, deformation is never homogeneous and, during the early stages of cratering, is always brittle, occurring by simple shear on fractures. Consequently, macroscale pure shear must be accommodated by more complex fault arrangements than the fracture networks associated with macroscale simple shear. It is therefore during rim growth that cataclasites and ultracataclasites are likely to form (Figure 13c).

Following rim growth, there is a relative hiatus of deformation as peak-ring material is transported inward toward the crater center. Nevertheless, during this movement, a substantial solid-body rotation of the peak-ring material occurs. Additionally, the maximum principal stress changes orientation from approximately radially to the hoop direction (Figure 12c). This change must cause the rearrangement of fault systems in the deforming peak-ring material such that previously utilized faults are abandoned and new 
faults form. This new fault arrangement is likely to be transpressional. This phase of deformation may therefore explain observed cross-cutting relationships between cataclasites (Figure 13d).

\subsection{Shear Faults}

As the peak-ring material becomes entrained into the central peak, pressures, deviatoric stresses, instantaneous strains, and strain rates substantially increase (Figure 9a). Greater strain rates are likely to lead to decreased spacing between deformation structures. Meanwhile, increased pressures from $\sim 10$ to $100 \mathrm{MPa}$ (respectively, corresponding to $\sim 300-\mathrm{m}$ and $\sim 3-\mathrm{km}$ depths at normal lithostatic conditions) for rocks that are at $\sim 650 \mathrm{~K}$ is likely to lead to a change in deformation mechanism. The observations of Riller et al. (2018) indicate that cataclasites and ultracataclasites, of which there are 258 recorded occurrences within the recovered core, are truncated by shear faults. The total number of shear faults in the recovered core is substantially greater than the number cataclasites, over 600 striated fault surfaces were measured (Riller et al., 2018), and these only represent the subset of shear faults that possess open surfaces. Consequently, it is clear that the spacing between the cataclasites and ultracataclasites, which formed early during cratering, is more than double the average spacing between the later deformation structures seen as cross-cutting shear faults. This relationship is qualitatively consistent with the increase in strain rate that occurs during central peak entrainment.

\subsection{Melt Intrusion and Deformation}

Once the central peak begins to collapse, peak-ring material moves outward atop the collapsed transient crater rim, now capped with material originally ejected from the transient cavity, and is itself capped by impact melt. As a consequence of the radially outward directed velocity field, the minimum principal stress changes orientation to the hoop direction. This stress regime causes maximum principal stretching in the hoop direction, which, in a natural system, would cause radially oriented, transtensional fault systems. Such faults may have facilitated the intrusion and mixture of impact melt and breccia bodies within the peak-ring material (Figure 13e).

The final phase of peak-ring formation, relaxation, occurs at strain rates beginning to approach conventional tectonic strain rates of $10^{-5} \mathrm{~s}^{-1}$ (Figure 9c) under stress conditions of normal failure, that is, $\sigma_{1}$ oriented vertically (Figure $12 \mathrm{e}$ ). The shocked target rocks in the peak ring are at $\sim 650 \mathrm{~K}$, while the impact melt rocks and suevitic breccias are likely to be at temperatures significantly in excess of $1000 \mathrm{~K}$. It is therefore no surprise that the last phase of impact deformation is brittle-ductile in the shocked target rocks and is ductile in the suevites and impact melt rocks. Additionally, the shear sense of these structures is always normal, amounting the maximum extension in the horizontal direction (Figure 13f).

\subsection{Discussion of Uncertainties}

Before proceeding to conclude this contribution, it is necessary to consider the uncertainties associated with the analysis of a numerical simulation in this way. Here, we have focused upon the stress-strain history of just one Lagrangian pseudo-cell. The exact location of this pseudo-cell does not directly correspond to the location of the recent IODP-ICDP drill core. The primary reason for this chosen difference is that Lagrangian tracer particles close to the free surface, where there is limited confining pressure, can behave without coherency to their neighboring tracer particles, thus removing any meaning from calculated strain information. Instead, the location of the selected pseudo-cell was chosen to be at the center of the peak-ring material, such that it would be representative of the deformation of the entire peak-ring structure. The stress-strain history of other pseudo-cells within the peak ring is quantitatively similar, to the one pseudo-cell presented here, with some systematic variations on properties such as material orientation (see supporting information; Figures S6-S8).

\section{Conclusions}

This work presents a detailed analysis of the temporal evolution of stress and strain within the peak-ring material of a numerical impact simulation. Our approach provides a template for directly comparing structural observations from impact structures with numerical impact simulations. This type of analysis allows for quantitative constraints on: the timing of deformation, the orientation, and the magnitude of strain asso- 
ciated with each stage of the impact cratering process and the orientation and magnitude of stress during shock, crater excavation, and crater modification.

The remarkable consistency between the stress-strain-time path of material within the Chicxulub peak ring during cratering with the complex sequence of observations of deformation from the recent IODP-ICDP drill core from the Chicxulub peak ring suggests that, kinematically, the dynamic collapse model of peak-ring formation is accurate. The kinematics of the model requires that one or more transient dynamical weakening mechanism operates and that the total effect of these mechanism(s) must be consistent with the rheological properties of the block model implementation of acoustic fluidization used here. Consequently, significant predictions can be made by the dynamic collapse model on the properties of rocks around complex craters, including but not limited to the orientation of faults, fractures, and microfractures; porosity and permeability structure and anisotropy; and the formation of frictionally generated pseudotachylites.

While the recent IODP-ICDP drill core and the importance of peak-ring formation motivated the focus of this work upon the deformation of peak-ring rocks, we emphasize that the same methodology has a general application. For example, directly related to this study, this type of analysis may provide further insight into large crater formation through a comparison between the three largest impact structures on Earth-Vredefort, Sudbury, and Chicxulub — which each provide access to structural deformation at different depths beneath the crater floor. Furthermore, detailed comparison between structural observations at terrestrial and extraterrestrial craters and their corresponding numerical simulations may be particularly insightful in revealing changes in deformation style between craters of different sizes or on different terrains.

\section{Appendix A: Expedition 364 Scientists}

S. P. S. Gulick ${ }^{1,2}$, J. V. Morgan ${ }^{3}$, E. Chenot ${ }^{4}$, G. L. Christeson ${ }^{2}$, P. Claeys ${ }^{5}$, C. S. Cockell ${ }^{6}$, M. J. L. Coolen ${ }^{7}$, L. Ferrière ${ }^{8}$, C. Gebhardt ${ }^{9}$, K. Goto ${ }^{10}$, S. Green ${ }^{11}$, H. Jones ${ }^{12}$, D. A. Kring ${ }^{13}$, J. Lofi ${ }^{4}$, C. M. Lowery ${ }^{2}$, R. Ocampo-Torres $^{14}$, L. Perez-Cruz ${ }^{15}$, A. E. Pickersgill ${ }^{16,17}$, M. Poelchau ${ }^{18}$, A. S. P. Rae ${ }^{2,18}$, C. Rasmussen ${ }^{4,19}$, M. Rebolledo-Vieyra $^{20}$, U. Riller ${ }^{21}$, H. Sato ${ }^{22}$, J. Smit ${ }^{23}$, S. M. Tikoo ${ }^{24}$, N. Tomioka ${ }^{25}$, J. Urrutia-Fucugauchi ${ }^{15}$, M. T. Whalen ${ }^{26}$, A. Wittmann ${ }^{27}$, L. Xiao ${ }^{28}$, K. E. Yamaguchi ${ }^{29,30}$.

${ }^{1}$ Department of Geological Sciences, Jackson School of Geosciences, University of Texas at Austin, Austin, TX, USA. ${ }^{2}$ Institute for Geophysics, Jackson School of Geosciences, University of Texas at Austin, Austin, TX, USA. ${ }^{3}$ Department of Earth Science and Engineering, Imperial College London, London, UK. ${ }^{4}$ Géosciences Montpellier, Université de Montpellier, Montpellier, France. ${ }^{5}$ Analytical, Environmental and Geo-Chemistry, Vrije Universiteit Brussel, Brussels, Belgium. ${ }^{6}$ Centre for Astrobiology, School of Physics and Astronomy, University of Edinburgh, Edinburgh, UK. ${ }^{7}$ Western Australia Organic and Isotope Geochemistry Centre (WA-OIGC), School of Earth and Planetary Sciences, Curtin University, Bentley, WA 6102, Australia. ${ }^{8}$ Natural History Museum, Vienna, Austria. ${ }^{9}$ Alfred Wegener Institute Helmholtz Centre of Polar and Marine Research, Bremerhaven, Germany. ${ }^{10}$ International Research Institute of Disaster Science, Tohoku University, Sendai, Japan. ${ }^{11}$ British Geological Survey, Edinburgh, UK. ${ }^{12}$ Department of Geosciences, Pennsylvania State University, University Park, PA, USA. ${ }^{13}$ Lunar and Planetary Institute, Houston, TX, USA. ${ }^{14}$ Groupe de Physico-Chimie de l'Atmosphère, L'Institut de Chimie et Procédés pour l'Énergie, l'Environnement et la Santé (ICPEES), Université de Strasbourg, Strasbourg, France. ${ }^{15}$ Instituto de Geofísica, Universidad Nacional Autónoma De México, Ciudad De México, Mexico. ${ }^{16}$ School of Geographical and Earth Sciences, University of Glasgow, Glasgow, UK. ${ }^{17}$ Argon Isotope Facility, Scottish Universities Environmental Research Centre, East Kilbride, UK. ${ }^{18}$ Department of Geology, University of Freiburg, Freiburg, Germany. ${ }^{19}$ Department of Geology and Geophysics, University of Utah, Salt Lake City, UT, USA. ${ }^{20}$ Independent consultant, Cancun, Mexico. ${ }^{21}$ Institut für Geologie, Universität Hamburg, Hamburg, Germany. ${ }^{22}$ Japan Agency for Marine-Earth Science and Technology, Kanagawa, Japan. ${ }^{23}$ Faculty of Earth and Life Sciences (FALW), Vrije Universiteit Amsterdam, Amsterdam, Netherlands. ${ }^{24}$ Earth and Planetary Sciences, Rutgers University, New Brunswick, NJ, USA. ${ }^{25}$ Kochi Institute for Core Sample Research, Japan Agency for Marine-Earth Science and Technology, Kochi, Japan. ${ }^{26}$ Department of Geosciences, University of Alaska Fairbanks, Fairbanks, AK, USA. ${ }^{27}$ Eyring Materials Center, Arizona State University, Tempe, AZ, USA. ${ }^{28}$ School of Earth Sciences, Planetary Science Institute, China University of Geosciences, Wuhan, China. ${ }^{29}$ Department of Chemistry, Toho University, Chiba, Japan. ${ }^{30}$ NASA Astrobiology Institute. 


\section{Appendix B: Author Contributions}

The work in this contribution was carried out during the PhD research of A. S. P. R. The PhD project was planned and supervised by J. V. M., G. S. C., R. A. F. G., and G. R. O.. T. D. and G. S. C. implemented code to iSALE such that postprocessing could be carried out. A. S. P. R. carried out the iSALE numerical simulations and postprocessing of the results. G. S. C., M. P., U. R., T. D., R. A. F. G., G. R. O., and J. V. M. contributed through discussions prior to the manuscript being written. A. S. P. R. wrote the first draft and all authors contributed to subsequent drafts.

\section{Appendix C: Data Availability}

iSALE is not a publicly available code; however, depending on usage terms, access is available upon request of the lead developers. Details of iSALE access are available at the iSALE website (www.isale-code.de). A GitHub repository containing additional supporting information pertaining to this contribution may be found at the GitHub website (https://github.com/ImperialCollegeLondon/Chicxulub_StressStrain; DOI: 10.5281/zenodo.1406165). The repository contains input files for the presented iSALE simulations and the pySALEPlot script used to calculate stress and strain. Data from IODP-ICDP Expedition 364 is available upon request from the IODP website (http://iodp.pangaea.de/).

\section{References}

The authors would like to thank Thomas Kenkmann, Nick Timms, and Jay Melosh for useful discussions and conversations that encouraged the development of this work. Additionally, we would like to thank Boris Ivanov and an anonymous referee for their detailed and constructive comments that significantly improved this paper. We gratefully acknowledge the developers of iSALE: Kai Wünnemann, Gareth Collins, Dirk Elbeshausen, Tom Davison, Boris Ivanov, and Jay Melosh Plots in this work were created with the pySALEPlot tool written by Tom Davison. The Chicxulub drilling expedition was funded by the IODP as Expedition 364 with cofunding from the ICDP. Expedition 364 was implemented by ECORD, with contributions and logistical support from the Yucatán state government and UNAM. The work presented here was funded by STFC (ST/N000803/1) and NERC (NE/P011195/1).
Allmendinger, R. W., Cardozo, N., \& Fisher, D. M. (2012). Structural geology algorithms: Vectors and tensors. New York: Cambridge University Press.

Amsden, A. A., Ruppel, H. M., \& Hirt, C. W. (1980). SALE: A simplified ALE computer program for fluid flow at all speeds (LA-8095). New Mexico: Los Alamos National Laboratories.

Anderson, C. E. (1987). An overview of the theory of hydrocodes. International Journal of Impact Engineering, 5(1-4), 33-59.

Benz, W., Cameron, A., \& Melosh, H. (1989). The origin of the Moon and the single-impact hypothesis III. Icarus, 81(1), $113-131$.

Chapman, C. R., \& McKinnon, W. B. (1986). Cratering of planetary satellites. In J. A. Burns \& M. S. Matthews (Eds.), Satellites (pp. 492-580). Tucson, AZ: University of Arizona Press.

Collins, G. S. (2014). Numerical simulations of impact crater formation with dilatancy. Journal of Geophysical Research: Planets, 119, 2600-2619. https://doi.org/10.1002/2014JE004708

Collins, G. S., Melosh, H. J., \& Ivanov, B. A. (2004). Modeling damage and deformation in impact simulations. Meteoritics \& Planetary Science, 39(2), 217-231.

Collins, G. S., Melosh, H. J., Morgan, J. V., \& Warner, M. R. (2002). Hydrocode simulations of Chicxulub crater collapse and peak-ring formation. Icarus, 157(1), 24-33. https://doi.org/10.1006/icar.2002.6822

Collins, G. S., Morgan, J., Barton, P., Christeson, G. L., Gulick, S., Urrutia, J., et al. (2008). Dynamic modeling suggests terrace zone asymmetry in the Chicxulub crater is caused by target heterogeneity. Earth and Planetary Science Letters, 270(3-4), 221-230. https://doi.org/10.1016/j.epsl.2008.03.032

Collins, G. S., Patel, N., Rae, A. S. P., Davies, T. M., Morgan, J. V., Gulick, S. P. S., \& Expedition 364 Scientists (2017). Numerical simulations of chicxulub crater formation by oblique impact. In 48th Lunar and Planetary Science Conference (Abstract 1832, pp. 20-24). The Woodlands, TX.

Davison, T. M., Collins, G. S., \& Bland, P. A. (2016). Mesoscale modeling of impact compaction of primitive solar system solids. The Astrophysical Journal, 821(1), 68. https://doi.org/10.3847/0004-637X/821/1/68

Dence, M. R. (1965). The extraterrestrial origin of Canadian craters. Annals of the New York Academy of Sciences, 123(2), 941-969. https://doi.org/10.1111/j.1749-6632.1965.tb20411.x

Dence, M. R., Grieve, R. A. F., \& Robertson, P. B. (1977). Terrestrial impact structures-principal characteristics and energy considerations. In D. J. Roddy, R. O. Pepin, \& R. B. Merrill (Eds.), Impact and explosion cratering (pp. 247-275). New York: Pergamon Press.

Elbeshausen, D., Wünnemann, K., \& Collins, G. S. (2009). Scaling of oblique impacts in frictional targets: Implications for crater size and formation mechanisms. Icarus, 204(2), 716-731. https://doi.org/10.1016/j.icarus.2009.07.018

Fossen, H. (2016). Structural geology (2nd ed.). Bergen, Norway: Cambridge University Press.

Fossen, H., \& Tikoff, B. (1993). The deformation matrix for simultaneous simple shearing, pure shearing and volume change, and its application to transpression-transtension tectonics. Journal of Structural Geology, 15(3), 413-422. https://doi.org/10.1016/0191-8141(93)90137-Y

Grady, D. E., \& Kipp, M. E. (1980). Continuum modelling of explosive fracture in oil shale. International Journal of Rock Mechanics and Mining Sciences \& Geomechanics Abstracts, 17(3), 147-157. https://doi.org/10.1016/0148-9062(80)91361-3

Grieve, R., Robertson, P., \& Dence, M. (1981). Constraints on the formation of ring impact structures, based on terrestrial data. In Multi-ring basins: Formation and evolution (pp. 37-57). New York and Oxford: Pergamon Press.

Gulick, S. P. S., Barton, P. J., Christeson, G. L., Morgan, J. V., McDonald, M., Mendoza-Cervantes, K., et al. (2008). Importance of pre-impact crustal structure for the asymmetry of the Chicxulub impact crater. Nature Geoscience, 1(2), 131. https://doi.org/10.1038/ngeo103

Gulick, S., Christeson, G., Barton, P., Grieve, R., Morgan, J., \& Urrutia-Fucugauchi, J. (2013). Geophysical characterization of the Chicxulub impact crater. Reviews of Geophysics, 51, 31-52. https://doi.org/10.1002/rog.20007

Hildebrand, A. R., Penfield, G. T., Kring, D. A., Pilkington, M., Camargo Z. A., Jacobsen, S. B., \& Boynton, W. V. (1991). Chicxulub crater: A possible cretaceous/tertiary boundary impact crater on the yucatan Peninsula, Mexico, Geology, 19(9), 867-871. https://doi.org/10.1130/0091-7613(1991)019<0867:CCAPCT>2.3.CO;2

Ivanov, B. A. (2005). Numerical modeling of the largest terrestrial meteorite craters. Solar System Research, 39(5), 381-409. https://doi.org/10.1007/s11208-005-0051-0 
Ivanov, B. A., Deniem, D., \& Neukum, G. (1997). Implementation of dynamic strength models into 2D hydrocodes: Applications for atmospheric breakup and impact cratering. International Journal of Impact Engineering, 17(1-5), 375-386. https://doi.org/10.1016/S0734-743X(97)87511-2

Ivanov, B. A., \& Kostuchenko, V. N. (1997). Block oscillation model for impact crater collapse. In 28th Lunar and Planetary Science Conference (Abstract 631, pp. 631). Texas.

Kring, D. A., Kramer, G. Y., Collins, G. S., Potter, R. W., \& Chandnani, M. (2016). Peak-ring structure and kinematics from a multi-disciplinary study of the Schrödinger impact basin. Nature Communications, 7(13), 161.

Le Feuvre, M., \& Wieczorek, M. A. (2011). Nonuniform cratering of the Moon and a revised crater chronology of the inner Solar System. Icarus, 214(1), 1-20. https://doi.org/10.1016/j.icarus.2011.03.010

Melosh, H. J. (1979). Acoustic fluidization: A new geologic process? Journal of Geophysical Research, 84(B13), 7513-7520. https://doi.org/10.1029/JB084iB13p07513

Melosh, H. J. (1989). Impact cratering: A geologic process, No. 11 In Oxford monographs on geology and geophysics. New York: Oxford University Press.

Melosh, H. J. (2005). The mechanics of pseudotachylite formation in impact events. In Impact tectonics (pp. 55-80). Berlin, Heidelberg: Springer. https://doi.org/10.1007/3-540-27548-7_2

Melosh, H. J., \& Ivanov, B. A. (1999). Impact crater collapse. Annual Review of Earth and Planetary Sciences, 27(1), 385-415. https://doi.org/10.1146/annurev.earth.27.1.385

Melosh, H. J., Johnson, B. C., \& Bowling, T. J. (2017). Impact spall and fragmentation by near-surface stress wave interactions. In 48th Lunar and Planetary Science Conference (Abstract 2051).

Melosh, H. J., Ryan, E. V., \& Asphaug, E. (1992). Dynamic fragmentation in impacts: Hydrocode simulation of laboratory impacts. Journal of Geophysical Research, 97(E9), 14,735-14,759. https://doi.org/10.1029/92JE01632

Morgan, J. V., Gulick, S. P. S., Bralower, T., Chenot, E., Christeson, G., Claeys, P., et al. (2016). The formation of peak rings in large impact craters. Science, 354(6314), 878-882. https://doi.org/10.1126/science.aah6561

Morgan, J., Gulick, S., Mellet, C. L., Green, S. L., \& the Expedition 364 Scientists (2017). Chicxulub: Drilling the K-Pg impact crater. Proceedings of the International Ocean Discovery Program, 364. College Station, TX: International Ocean Discovery Program. https://doi.org/10.14379/iodp.proc.364.2017

Morgan, J., Warner, M., the Chicxulub Working Group, Brittan, J., Buffler, R., Camargo, A., et al. (1997). Size and morphology of the Chicxulub impact crater. Nature, 390(6659), 472-476. https://doi.org/10.1038/37291

Penfield, G. T., \& Camargo, Z. A. (1981). Definition of a major igneous zone in the central Yucatan platform with aeromagnetics and gravity, Technical program, abstracts and biographies (Society of Exploration Geophysicists 51st Annual International Meeting): Los Angeles (pp. 37). College Station, TX: Society of Exploration Geophysicists.

Pierazzo, E., Kring, D. A., \& Melosh, H. J. (1998). Hydrocode simulation of the Chicxulub impact event and the production of climatically active gases. Journal of Geophysical Research, 103(E12), 28,607-28,625.

Pierazzo, E., Vickery, A. M., \& Melosh, H. J. (1997). A reevaluation of impact melt production. Icarus, 127(2), 408-423. https://doi.org/10.1006/icar.1997.5713

Pike, R. J. (1974). Depth/diameter relations of fresh lunar craters: Revision from spacecraft data. Geophysical Research Letters, 1(7), 291-294.

Ramesh, K. T., Hogan, J. D., Kimberley, J., \& Stickle, A. (2015). A review of mechanisms and models for dynamic failure, strength, and fragmentation. Planetary and Space Science, 107, 10-23. https://doi.org/10.1016/j.pss.2014.11.010

Ramsay, J., \& Huber, M. (1983). The techniques of modern structural geology: Strain analysis (Vol. 1). London, New York: Academic Press.

Riller, U., Poelchau, M. H., Rae, A. S. P., Schulte, F. M., Collins, G. S., Melosh, H. J., et al. Expedition 364 Science Party, IODP-ICDP (2018) Rock fluidization during peak-ring crater formation. Nature, 562(7728), 511. https://doi.org/10.1038/s41586-018-0607-z

Shoemaker, E. M. (1962). Interpretation of lunar craters, Physics and astronomy of the Moon (pp. 283-359). New York: Elsevier.

Thompson, S. L., \& Lauson, H. S. (1974). Improvements in the CHART D radiation-hydrodynamic code III: Revised analytic equations of state (SC-RR-710714). Alberquerque, New Mexico: Sandia National Laboratory.

Tikoff, B., \& Fossen, H. (1995). The limitations of three-dimensional kinematic vorticity analysis. Journal of Structural Geology, 17(12), 1771-1784. https://doi.org/10.1016/0191-8141(95)00069-P

Wünnemann, K., Collins, G. S., \& Melosh, H. J. (2006). A strain-based porosity model for use in hydrocode simulations of impacts and implications for transient crater growth in porous targets. Icarus, 180(2), 514-527. https://doi.org/10.1016/j.icarus.2005.10.013 